\title{
PERFORMANCE EVALUATION OF A HYBRID ROUNDABOUT USING A MICROSCOPIC SIMULATION
}

\author{
YAVUZ USER ${ }^{1 *}$, SEYITALI ILYAS ${ }^{2}$, GULTEKIN TINAZTEPE ${ }^{3}$ \\ ${ }^{1}$ Akdeniz University, Department of Electrical and Electronic Engineering \\ Department, Antalya, Turkey \\ ${ }^{2}$ Antalya Metropolitan Municipality, Department of Transportation \\ Planning and Rail Systems, Antalya, Turkey \\ ${ }^{3}$ Akdeniz University, Vocational School of Technical Sciences, \\ Mathematics Program, Antalya, Turkey
}

Received 9 November 2020; accepted 22 April 2021

\begin{abstract}
Roundabouts are one of the safest types of intersections. There are a number of roundabout types in literature. Each roundabout type is distinguished by some characteristics. To design more efficient junctions, hybrid roundabouts can be created by combining their required characteristics geometrically. In this study, the safety feature of the turbo junction type and the easing up the traffic density feature of the hamburger junction have been combined. Some geometric parameters and layout details of the proposed hybrid roundabout are given, and its performance was simulated in a signalised 4-leg roundabout as the most frequently used intersection in Antalya. The performance of the proposed hybrid roundabout was compared with the status in 2016 and the current status in 2017 and beyond of the roundabout through AIMSUN transport simulation software. In regard to performance
\end{abstract}

* Corresponding author. E-mail: yuser@akdeniz.edu.tr

Yavuz USER (ORCID ID 0000-0002-9903-2074)

Seyitali ILYAS (ORCID ID 0000-0003-2009-3454)

Gultekin TINAZTEPE (ORCID ID 0000-0001-7594-1620)

Copyright (C) 2021 The Author(s). Published by RTU Press

This is an Open Access article distributed under the terms of the Creative Commons Attribution License (http://creativecommons.org/licenses/by/4.0/), which permits unrestricted use, distribution, and reproduction in any medium, provided the original author and source are credited. 
analysis, delay time, travel time, speed, density, fuel consumption, number of stops, queuing, carbon emission were analysed for all statuses and compared. In addition, traffic safety analysis has been performed for all statuses and

compared. Results show that the overall average performance of the proposed roundabout increases by $40 \%$ and $41.8 \%$ in comparison with the statutes in 2016, 2017 and beyond, respectively. The proposed roundabout is $41 \%$ safer than the status in 2016, and the accident risk is lower by $18.5 \%$ than the current status.

Keywords: comparative analysis, geometric model, hamburger roundabout, microscopic simulation, signalised intersection, turbo roundabout.

\section{Introduction}

The growth of population, technological advances and correspondingly the increasing number of vehicles induce the insufficiency of roads in many countries. To provide more comfortable and fast transportation, the parameters such as the systems of transportation, the routes, types of junctions and also the traffic signalisation should be evolved.

One of the most important parameters having effect on the traffic flow is the intersection where two or more traffic flows coming from different directions meet, cross or diverge. Since each vehicle involved in an intersection performs a series of different manoeuvres, there is a quite high possibility of an accident. Some road safety controls are performed at intersections in order to prevent the occurrence of an accident. Location of a central island and signalisation are some of the traffic audit techniques, which yields to the concept of roundabout.

In spite of common worldwide usage with successful operational performance, there has been little consensus about the ideal roundabout design criteria (Tollazzi, \& Renčelj, 2014). The existence of various traffic conditions and environmental requirements in different countries bring about many types of roundabouts, which address different traffic issues.

Many studies have shown that standard two-lane roundabouts have weak traffic safety characteristics and a low capacity. Because of the lack of sign usage for route selection, there are various conflict points caused by lane-change when vehicles are coerced to slow down due to the geometric properties of the central island, which may result in sideby-side collisions (Corriere \& Guerrieri, 2012). In an attempt to solve these problems, a new type of roundabout, called turbo roundabout, was applied in the Netherlands in 1996 by Fortujin (2009).

Over past few decades, especially, in the European countries, turbo roundabouts come to the forefront due to their superior safety feature, which stems from the geometric design reducing conflict points. It 
is shown that there is a significant decrease in the number of injuries/ deaths in turbo roundabouts; even in some studies, $80 \%$ decrease has been measured (Fortuijn, 2009). In spite of their superior safety feature, Evaluation of a Hybrid Roundabout Using a Microscopic in comparison with conventional roundabouts, improvement of the capacity is controversial (Vasconcelos et al., 2014).

Although the traffic safety is quite an important criterion in design and implementation of the intersection, the operational performance of the roundabout must be taken into consideration. The intersection should be designed such that it has a high level of capacity and service; on the contrary, a low level of delay and negative environmental effects (Tollazzi \& Renčelj, 2014). In this regard, hamburger (through-about or cut-through) roundabouts have been used for almost a century, which reduce the delay time and ease the traffic flow due to a transitional island (Brown, 1995).

On the other hand, implementation of the roundabout layout is as significant as the determination of proper design (Goncharenko, 2018). Designing the best roundabout satisfying required features, the experimental field studies have been always obligation to test its efficiency. Today, these studies are performed in silico. Sophisticated traffic simulation software enables experimental field studies to be carried out in a safer, cheaper and faster way. Also, processing the current traffic data and considering different traffic scenarios help find the optimum designs and to innovate roundabout ideas. In recent years, many studies have been carried out on microscopic-simulation applications for traffic management on roundabouts, some of which are presented in the second section.

In this study, an alternative hybrid roundabout was proposed by combining the superior features of the turbo and hamburger intersections. The proposed roundabout has been adapted to the intensively used Sampi intersection in Antalya. Safety analysis, performance analysis and comparisons for traffic parameters, including density, speed, number of stops, delay time, fuel consumption, travel time, carbon emission, were performed by AIMSUN for three statuses of Sampi intersection: 2016, after 2017 (current status) and the proposed roundabout status.

The organisation of the paper is as follows. In the second section, comprehensive literature review is given. In the third section, the geometric design and layout of the proposed roundabout are presented, also signal plans are provided for the proposed roundabout via simulation parameters and compared. In the fourth section, the parameters, including density, speed, number of stops, delay time, fuel consumption, travel time, carbon emission, for the three status of intersection are analysed and compared, also accident risk analysis 
is presented. In the fifth and sixth sections, the results of performance analysis are discussed and interpreted.

\section{Literature review and motivation}

Since the intersections are a ubiquitous tool of traffic management around the world, there have been numerous studies addressing different aspects, such as safety, capacity, delay time, emission, travel time etc. In the following subsections, a compilation of the most related studies is presented.

\subsection{Intersection and overview}

It is only possible to manage the traffic with uncontrolled roundabouts when traffic flows are minimal. With the increasing traffic flows at roundabouts, many problems such as traffic congestion and traffic accidents have started to happen. Kettil and Wiberg (2002) indicate that the most efficient state of the intersection can be identified with high accuracy simulation programs. Lee et al. (2003) conclude that when the results are obtained through modelling the intersection performance with HCM method and Sidra, the basic parameters such as $\mathrm{v} / \mathrm{c}$ ratio, delay and queuing estimation are similar.

De Brabander and Vereeck (2007) show that alternative roundabouts reduce accidents at a great extent. However, this is pursuant to the speed limit on the main road and other roads. Wu et al. (2015) mention that with the implementation of signalisation, accidents have been effectively reduced at alternative roundabouts. The study of Yilmaz and Kose (2007) indicates that the intersection must be designed to meet high capacity and high level of security. The geometric features of the intersection are of great importance in terms of the capacity of the highway and traffic safety. Increasing number of vehicles have led to traffic congestion in many cities' road network due to population density. To reduce the traffic congestion, a traffic flow may be regulated through a recommended model, which is created by using a computer and does not impose any infrastructure costs. If the recommended model turns out to be functional, it can be applied. Thus, maximum efficiency is ensured with minimum cost.

In the study of Qian et al. (2008), signalised roundabouts, where warehousing activities take place at left-turns around the island, are compared with partially-controlled signalised roundabouts. It has been concluded that signalised roundabouts are an efficient solution to eliminate the crossing of vehicles and intersection congestion 
problems at the intersections where the traffic flow is regular and heavy. Evaluation of a Hybrid Mandavilli et al. (2008) assert that signalised intersections reduce the speed of vehicle traffic in certain situations and in some cases even stop Roundabout Using a Microscopic traffic, and this results in a significant increase in vehicle emissions. In addition, the new alternative roundabouts designed have an impact of improving the traffic flow, reducing the time wasted by the vehicles at the intersection, and by extension reducing fuel consumption and vehicle emissions at the intersection. The studies also show that alternative roundabouts are eco-friendly.

Bai et al. (2010) show that signal control arrangement is a subsidiary factor for improving the delay and safety at the roundabout and the radius, and different circuit times of the central island at the roundabout have a significant impact on vehicle delay. Akçelik (2011) shows that the roundabout analyses can be performed by studying the actual traffic volumes and the actual geometric characteristics of the intersection.

\subsection{Alternative roundabout types and their comparison}

Literature review has revealed that many types of roundabouts have been suggested around the world. Despite the fact that roundabouts have been used widely in recent years, the design criteria have not been clarified yet. There is no clear-cut method, which is proposed for the design of phase plan and optimal signal duration for approach arms and flows around the island. The performance of these intersections can only be determined with some simulation programs or intuitively and empirically with experts (Cakıcı \& Tian, 2019). Therefore, there are a lot of local informative guides for roundabout design published by the relevant institutions of different countries (Ess \& Antov, 2017). The introduction of turbo roundabout first used in the Netherlands in 1996 by Fortuijn (2009) marked a new approach in roundabout design. During few decades following the emergence of turbo roundabout, a vast number of studies have been conducted to assess its operational performance in comparison with conventional and other alternative designs of multilane roundabouts with or without signalisation. Many of them set forth the advantage of turbo roundabouts with respect to traffic parameters such as delay time, speed, travel times, emission, capacity, queuing in certain conditions, but most of them indicated the decrease in conflict points, i.e., minimising accident risk as a salient feature of turbo roundabout.Turbo and hamburger roundabouts are compared to conventional and other alternative types of roundabout. Since each study focuses on the comparison according to several traffic parameters, the related literature is given in chronological order for the sake of clarity. 
The study of Mauro and Branco (2010) indicates that the target roundabout is compared with the standard roundabouts in the same traffic density; it is stated that crossing conflict points, delay times and queuing are reduced, and target roundabout is much more efficient. Tollazzi et al. (2013) find the superiority of turbo roundabout over double-lane roundabouts in terms of capacity.

In study of Tollazzi and Rencelj (2014), hamburger intersection was only defined, and its rough sketch drawings were made, it was not analysed from different directions. Tollazzi (2014) indicates that the hamburger and dumb-bell intersection types are widely used in the world. Hamburger intersection is constructed as a one- or two-level roundabout. Tollazzi and Rencelj (2014) compare turbo roundabout with flower roundabout in terms of design by VISSIM; it is concluded that the flower roundabout is safer and has fewer conflict points. In regard to capacity, turbo roundabout is more advantageous because there are different types of turbo roundabouts for different direction of traffic flow, but the flower roundabout is more advantageous in terms of traffic safety. Silva et al. (2014) show that the number of conflicting points and speed of vehicles in the intersection decrease at turbo roundabout, that there are 24 conflicting points at double-lane roundabout whereas there are 14 conflicting points at turbo roundabout when double-lane standard roundabout is compared to turbo roundabout.

Tollazzi et al. (2016) compare turbo roundabouts to alternatives (turbo, flower, target and four-flyover intersections). They found that the results were similar when the standard roundabouts were compared to alternative roundabouts if the number of vehicles entering the intersection was low, and that the results were different if the number of vehicles increased. The target roundabout has a lower delay compared to other intersections. The four-flyover roundabout has better results when left turns are intense. The number of conflicting points decreases at alternative roundabout types much more than it happens at standard roundabouts.

In a study by Skvain et al. (2017); Džambas et al. (2017) it is seen that turbo roundabouts are more advantageous when traffic accident data and also capacity of the conventional types of intersections are transformed into the turbo roundabouts in the Czech Republic. Hatami and Aghayan (2017) conclude that an increase in the diameter of central island and speed limits has effects on delay time and capacity. If turbo roundabout is compared with elliptic and modern intersections with or without signalisation, it is observed that the increase has a positive effect on delay time and capacity in all signalised intersections under all flow conditions. Chenwei and Xiaodan (2017) conclude that the HCM 2000 delay model and traffic model theory can be used in the plan and 
design of the hamburger roundabout and it reflects the delay parameter Evaluation of a Hybrid well.

Izadi et al. (2016); Dabiri et al. (2020) assert that when conventional Roundabout Using a Microscopic and turbo roundabouts are compared to conventional roundabouts in different scenarios with respect to performance of delay time, capacity and level of service, in case that the diameter of the four-leg turbo roundabout is increased, the performance of the conventional roundabout decreases but the performance of the three-leg turbo roundabout increases. Liu et al., (2020) conclude that when turbo roundabouts with different central island diameters are designed, the performance of the roundabout can change according to the number of legs. Also, in a study carried out by Elhassy et al. (2020) in Doha, a city of Qatar, three modified versions of rotor turbo roundabouts were designed and compared to the conventional roundabout in terms of capacity, queuing, delay time. It was asserted that rotor turbo roundabouts were not suitable for intersections with high traffic volume exceeding 4500 vehicles in comparison with conventional roundabouts.

\subsection{Motivation}

There have been very similar studies to this work suggesting an alternative design involving turbo roundabouts and hamburger roundabouts. Two of them can be given as examples. A study conducted by Kolak et al. 2015 in Osijek, a city of Croatia, suggests a turbo roundabout instead of two-lane elliptical roundabout where a tramline passes through the central island. In this study, performance analyses are made with respect to queuing and delay time and only tramline passes through the central island.

In another study by Aakre and Aakre (2017) at an intersection in Hillevag, a city in Stavanger in Norway, a design of continuous median lane roundabout (CMLR) with absolute bus priority is suggested. When it is analysed via microscopic simulation by AIMSUN, it is shown that while traffic flow coming to the current roundabout is controlled by signalisation, it is sufficient to use a yield sign in CMLR. In this study, performance analysis is made with respect to delay time and emission.

As seen above, the comparison of different types of intersection is one of the common studies in literature. Each type of intersections has strengths and weaknesses in regard to characteristics. Most of the studies compare an existing type with another type or a conventional roundabout with respect to few traffic parameters. What sets this work apart from most of the relevant studies is the focus on combining superior features of the existing types to design a hybrid roundabout. On the other hand, most of the relevant studies present a performance 
analysis with respect to few parameters. This study suggests the overall performance analysis in terms of traffic parameters, including queuing, emission, delay time with further details of hybrid geometry and safety analysis.

\section{Material Method}

\subsection{General characteristics of the roundabout to be simulated}

It refers to the 4-arm signalised roundabout where Burhanettin Onat Street, Tevfik Işık Street, Metin Kasapoglu Street and Portakal Cicegi Street intersect. Vehicle traffic density is in the direction of Burhanettin Onat Street-Metin Kasapoglu Street, which is the main artery and in the direction of Portakal Cicegi Street leading to the tourism area. In case of 2016, there were 3 lanes from Burhanettin Onat Street to junction, 3 lanes from Metin Kasapoglu Street to junction, 3 lanes from Tevfik Işık Street to junction. In the case of current status, there are 4 lanes from Burhanettin Onat Avenue to the junction, 4 lanes from Metin Kasapoglu Avenue, 2 lanes from Portakal Cicegi Avenue, and 2 lanes from Tevfik Işılk Avenue. In case of the proposed roundabout, there are 4 lanes from Burhanettin Onat Street, 3 lanes from Metin Kasapoglu Street, 2 lanes from Portakal Cicegi Street, 2 lanes from Tevfik Ișık Street. The view of the roundabout in 2016 and its drawing are shown in Fig. 1.
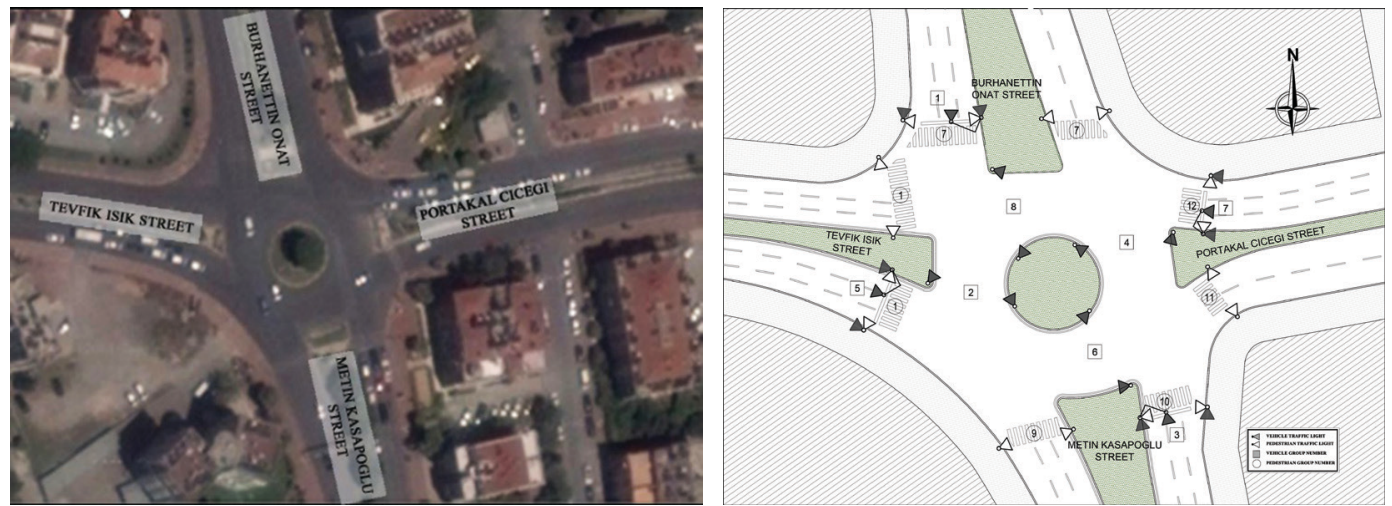

Figure 1. The image and plan view of Burhanettin Onat Street - Metin Kasapoglu Street roundabout in 2016 (by maps.google.com and by S. Ilyas, Y. User, respectively) 
AutoCAD drawing will be used as a base plate in AIMSUN program. Evaluation of a Hybrid Roundabout Using Frames represented by $1,2,3,4,5,6,7,8$ refer to car group numbers. Circles represented by $1,7,9,10,11,12$ refer to pedestrian group a Microscopic numbers. The intersection current view and AutoCAD drawing that will be used as a base plate are shown in Fig. 2. Frames represented by 1, 2, 3, 4 refer to car group numbers. Circles represented by 5, 6, 7, 9, 10, 11, 12 refer to pedestrian group numbers.

AutoCAD drawing of the designed proposed hybrid roundabout is shown in Fig. 3. The traffic density on Burhanettin Onat Street will be greatly reduced as the direct connection road situated within Turbo roundabout island, that is distinguished by its safe intersection property, enables direct connection from Burhanettin Onat Street arrival arm to Portakal Cicegi Street departure arm. Frames represented by 1, 2, 3, 4, 5 , $6,7,8$, F refer to car group numbers. Pedestrian groups are not included in the simulation.

\subsection{Layout and geometry of the proposed roundabout}

The intersection to be studied is a four-leg multilane intersection as mentioned in the previous section. Some geometric parameters of the roundabout for three designs are seen in Table 1. The proposed design will be a union of two types of roundabouts, namely, turbo and hamburger.

To construct the turbo block, a union of two Archimedean spirals is used. Spiral separation of lanes provides safe circulation by preventing the weaving, since it obligates the driver to choose the lane before entering. After the turbo block is created, direct left-turn lane passing
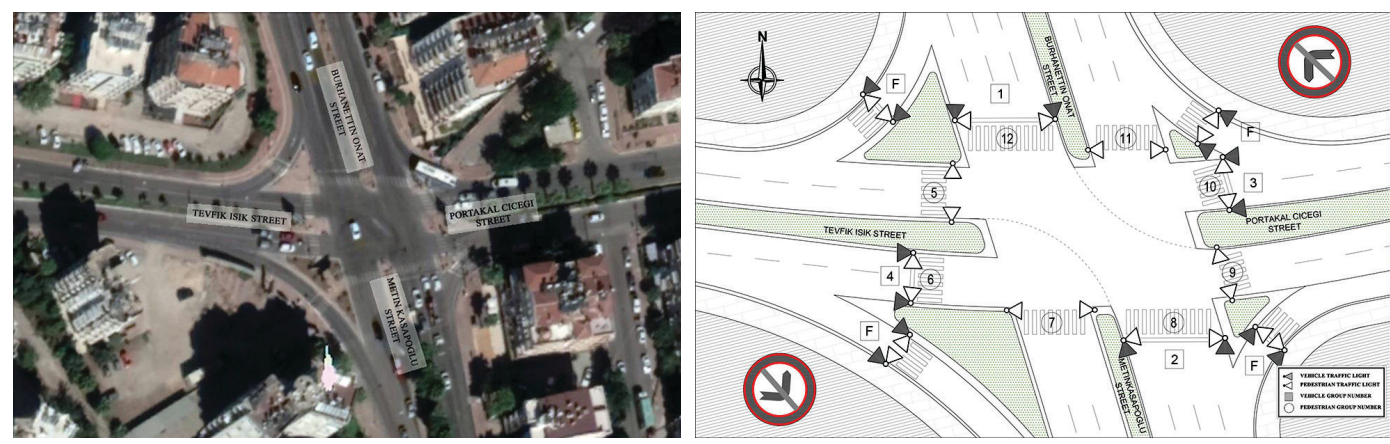

Figure 2. The image and plan view of Burhanettin Onat Street - Metin Kasapoglu Street roundabout in current status (by maps.google.com and by S. Ilyas, Y. User, respectively) 
through the central island is created. This lane connects the entering lane on Burhanettin Onat arm to exiting lane on Portakal Cicegi arm. It is clear from Table 3 that the highest number of entering vehicles into circulatory lanes are the number of the vehicles turning (left) to the Portakal Cicegi arm. This rerouting for left-turning vehicles as indicated in Fig. 10 reduces the number of entering vehicles in circulating, conflicting vehicular volume, also allows the drivers to turn left safer at a higher speed. In this layout, a conic curve is considered for the geometry of direct left-turn lane. In this simulation, this conic curve is found as an ellipse arc. Some calculations are given for the determination of this curve. In the following subsections, some details about the process are given. The process is expressed briefly as follows:

First, the Archimedean spiral and its formula and symmetric spiral (hence, union of these spirals) are introduced into the Cartesian coordinate plane, which is used to make circulatory lanes and central island. The spiral formula and number of cycles are determined with respect to the required number of lanes. Then, to construct the left-turn lane on the island, two points $A_{1}$ and $A_{2}$ are chosen on the suitable cycle

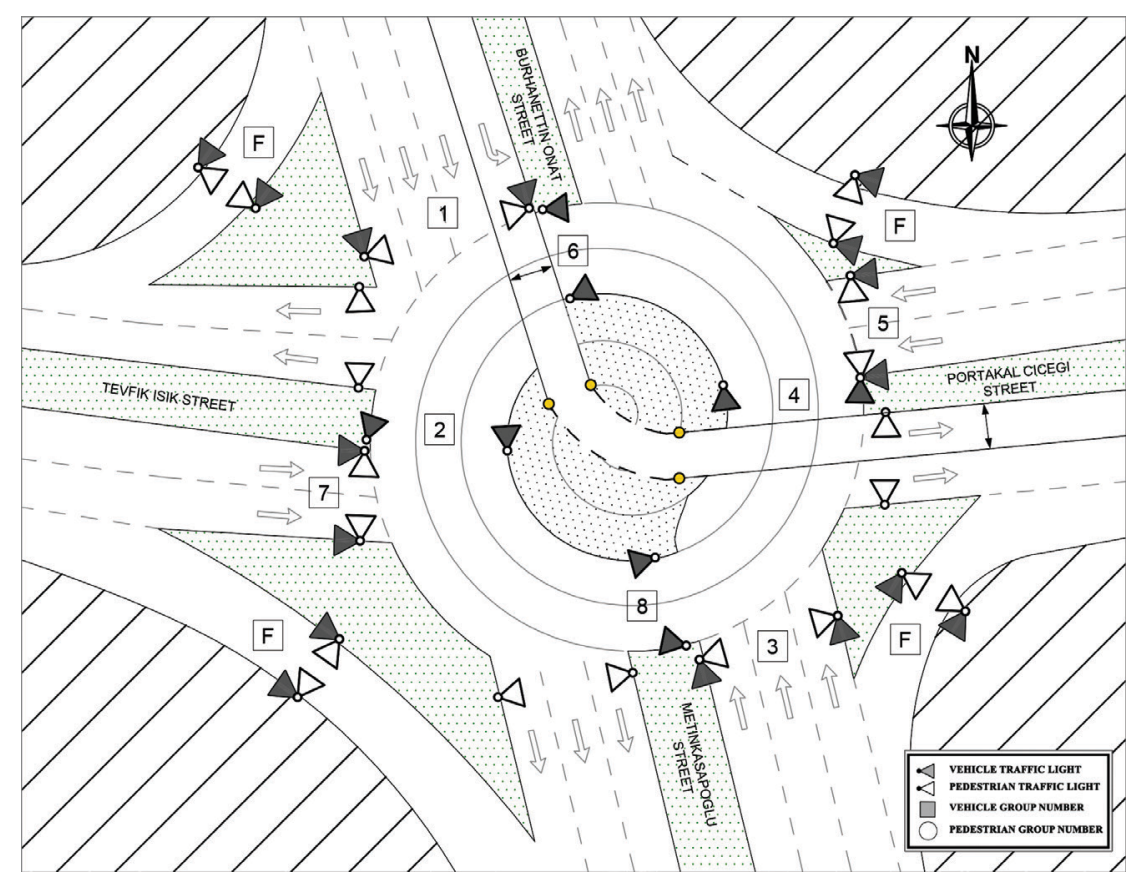

Figure 3. The plan view of Burhanettin Onat Street - Metin Kasapoglu Street roundabout for the proposed design (by Y. User \& S. Ilyas) 
of spirals. Corresponding points $\mathrm{B}_{1}$ and $\mathrm{B}_{2}$ are determined with respect Evaluation of a Hybrid to the width of lane. $A_{1}, B_{1}$ and $A_{2}, B_{2}$ represent the end points of edge lines of entering lane and initial points of edge lines of exiting lane, Roundabout Using a Microscopic respectively. Then the equation of the conic arc that connects $A_{1}$ and $A_{2}$ is investigated under some certain conditions such as being tangent on those points to the axes of edge lines of entering and exiting lanes. In this study, an arc is found as an ellipse arc which is given by a parametric equation.

The turbo roundabout and archimedes spiral

For the determination of the circulatory lanes, the combination of two spirals is used. These spirals are Archimedes spiral (Fig. 4) and symmetric spiral with respect to $y=-x$ line (Fig. 5). The Archimedes spiral is characterised by the fact that a line drawn outward from the centre of the spiral is equal in length between points at which the spiral intersects the curves. However, this length is not the same for all angles. These lengths are equal for the curve created by the combination of Archimedes spiral and its symmetric spiral (Fig. 6).

\section{Placement of the lanes to be connected by direct turn-left lane on cartesian coordinate system}

To make calculations for determination of the direct left-turn lane on the central island easier, the entering lane on Burhanettin Onat arm and the exiting lane on Portakal Cicegi arm providing left-turn are shown

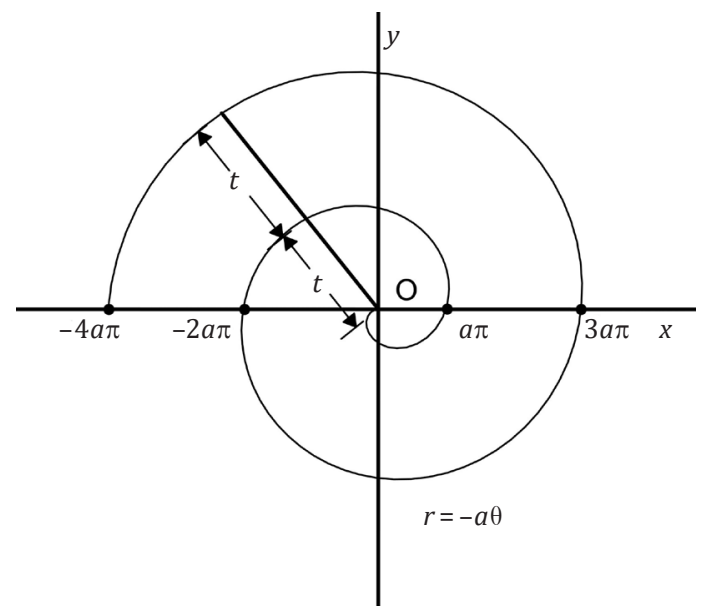

Figure 4. The Archimedean spiral $r=a \theta$ for $0<\theta<4 \pi$

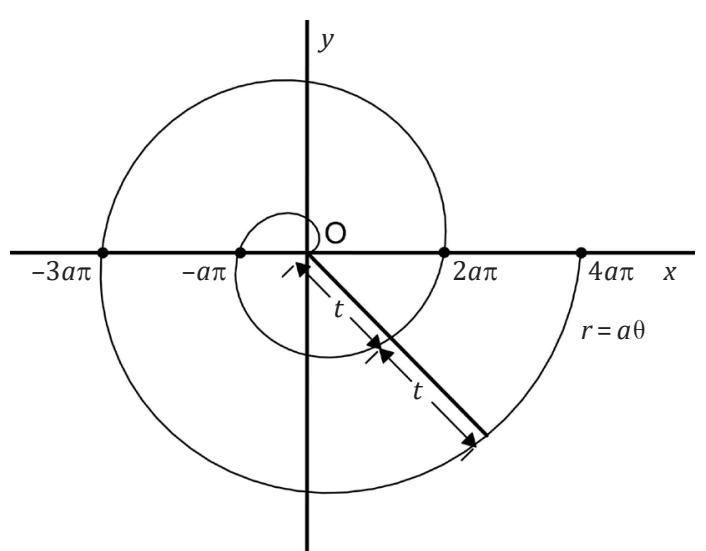

Figure 5. The symmetric spiral $r=-a \theta$ for $0<\theta<4 \pi$ 


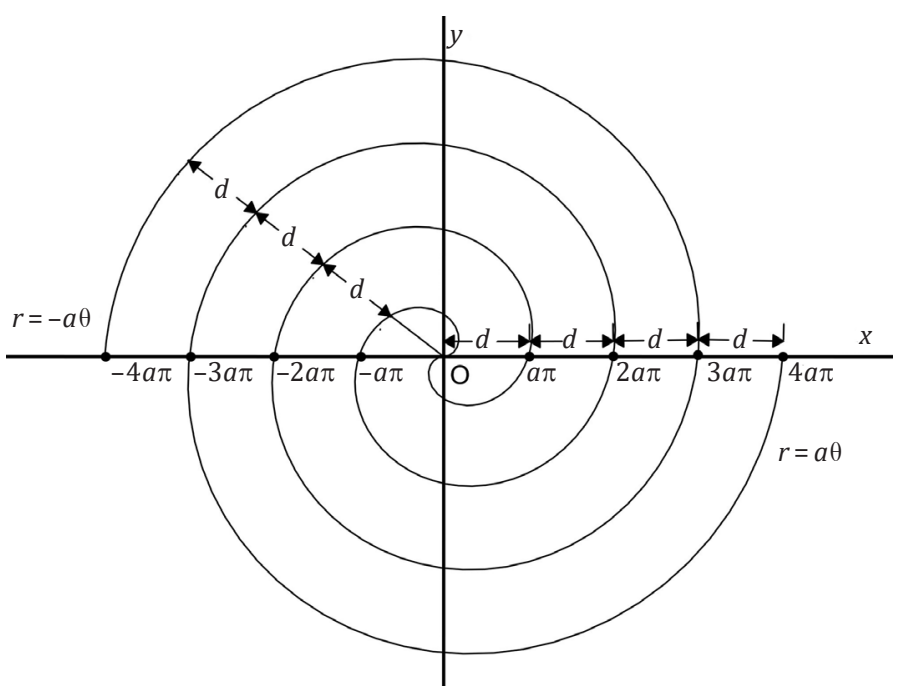

Figure 6. The combination of spirals $r=a \theta$ and $r=-a \theta$ for $0<\theta<4 \pi$

in Cartesian system in Fig. 7a. In the figure, the point 0 is the centre of roundabout, the centrelines of Burhanettin Onat and Portakal Cicegi legs are denoted as dash-dotted lines, Portakal Cicegi leg centreline coincides with $x$ axis. $\alpha$ is the angle between Burhanettin Onat leg centerline and $y$ axis. The points $A_{1}, A_{2}$ are the chosen points where edge lines of the entering lane and exiting lane meet on the chosen cycles of united spirals, respectively. The points $\mathrm{B}_{1}$ and $\mathrm{B}_{2}$ on lane edge lines correspond to the points $A_{1}$ and $A_{2}$. Edge lines of entering and exiting lanes are denoted by the lines $I_{\mathrm{A}_{1}}, I_{\mathrm{A}_{2}}$ and $I_{\mathrm{B}_{1}}, I_{\mathrm{B}_{2}}$ respectively. $d$ is the width of these lanes. $s_{2}$ represents the distance between the edge line of exiting lane and (the centreline of Portakal Cicegi leg) $x$ axis. $s_{1}$ represents the distance between the edge line of entering lane and $y$ axis. $R$ denotes the inscribed circle diameter. For the sake of clarification, the illustrative placement of the roundabout is given in Fig. 7b.

\section{Identification of spiral formula}

According to the inscribed circle diameter of a roundabout and the number of its circulating lanes, spiral formula and the number cycle of spiral are determined. For a roundabout whose inscribed circle diameter is $R$ meter and the cycle number $n$, the coefficient $a$ in the spiral formula is calculated as $a=R / 4 \pi n$. 
Yavuz User,

Seyitali ilyas,

Gultekin Tinaztepe

Performance

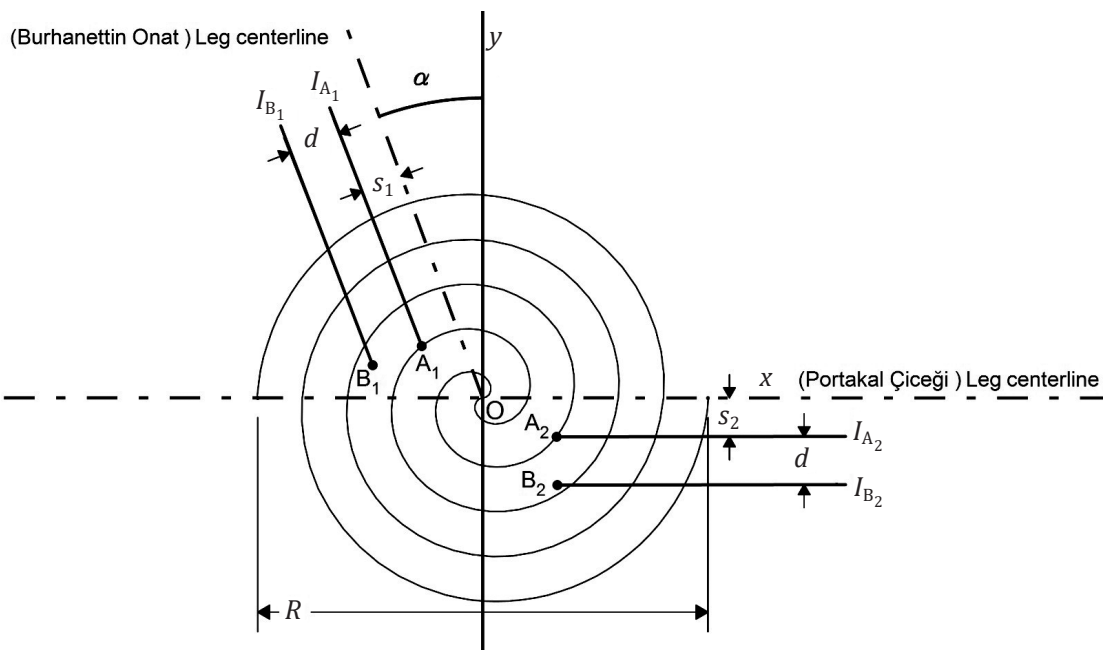

Evaluation of a Hybrid

Roundabout Using

a Microscopic

Simulation

Figure 7a. Placing the proposed roundabout design into Cartesian coordinate system (by Y. User)

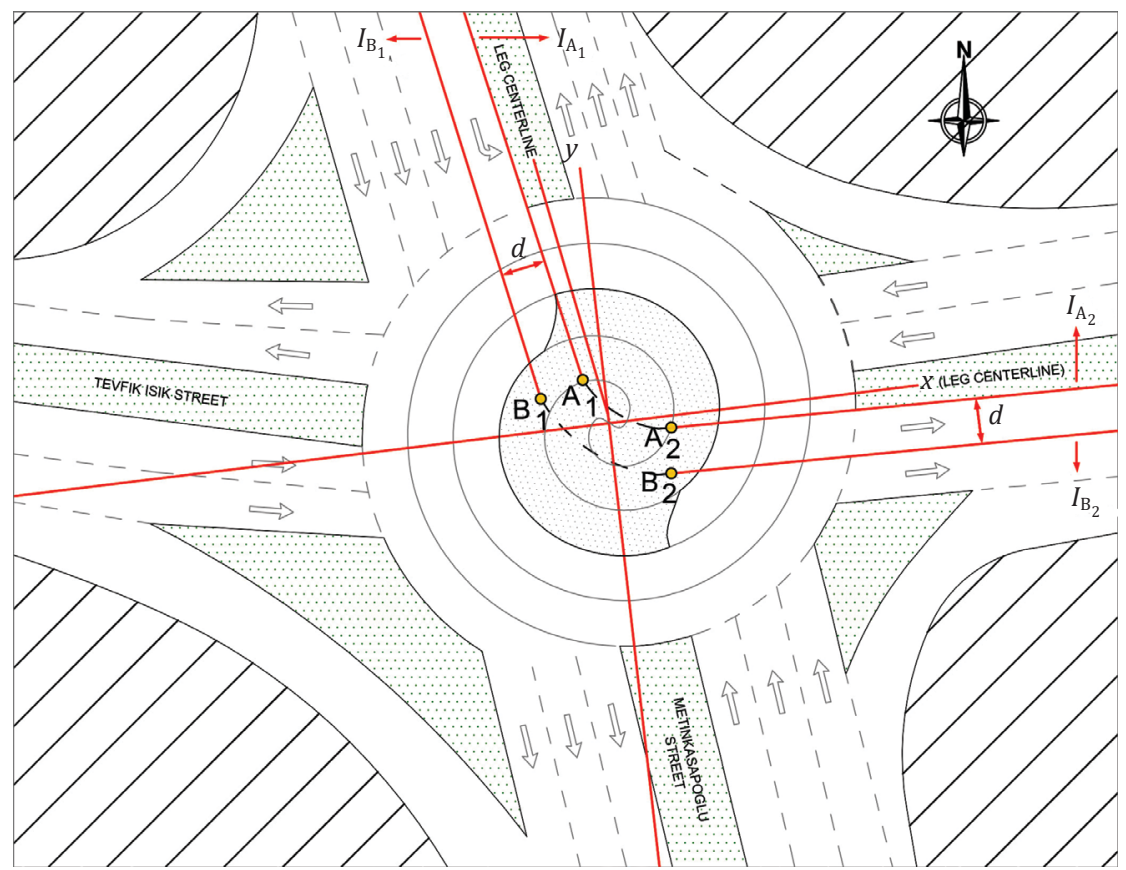

Figure 7b. Illustrative roundabout (by G. Tinaztepe) 


\section{Selection and identification of the location of connecting points for left-turn curve}

For this application, $A_{1}$ and $A_{2}$ points are selected on the 1st cycle of $r=-a \theta$ and $r=a \theta$ parts of the spiral combination, respectively, $(0<\theta 2 \pi)$ and calculations are carried out by considering this fact. This calculation can be adjusted if the points are on the other cycles of the same part $(r=a \theta)$ of spiral combination or on the cycles of another part of spiral combination.

By using spiral and line equations, the coordinates of $\mathrm{A}_{2}$ where spiral with $r=a \theta$ and $I_{\mathrm{A}_{2}}$ intersects are found to be $\mathrm{A}_{2}\left(r \cos \theta,-s_{2}\right)$. Likewise, $\mathrm{A}_{1}$ is found to be $\mathrm{A}_{1}(r \cos \theta, r \sin \theta)$. The location of $\mathrm{B}_{1}$ and $\mathrm{B}_{2}$ points can be easily found by considering the fact that $B_{1}$ and $B_{2}$ points are respectively at a $d$ unit distance from $A_{1}$ and $A_{2}$ points.

\section{Determination of the turn-left curve}

In this roundabout layout, to provide traffic flow from Burhanettin Onat arm to Portakal Cicegi arm, a direct left-turn lane passing through the central and joining the points $A_{1}$ and $B_{1}$ with the points $A_{2}$ and $B_{2}$, respectively, is considered. It is a well-known fact that the connecting curve joining tangent section and circular curve of the way is needed to decrease the lateral acceleration in high-speed roadways gradually to prevent drivers from encroaching into adjoining lanes or skidding. Since this crossroad which is selected for our work is inside the city, the speed of the vehicles is low. Moreover, the speed of the vehicles will decrease more at the crossroads especially. Also, the super-elevation is not needed in this curve because of the mentioned causes. Thus, any proper curve can be used to connect these points.

In this work, a connecting curve is selected as a conic curve. The determination of the equation of this conic connecting $A_{1}$ and $A_{2}$ is given below. Then the curve connecting $B_{1}$ and $B_{2}$ will be determined parametrically. As it can be seen in Fig. 8, there are an infinite number of conics passing through the points $\mathrm{A}_{1}$ and $\mathrm{A}_{2}$. Among these conics, the conic which is the most suitable for vehicle entrance to this lane must be selected. Considering that A, B, C, D, E, F are real numbers, a general conic equation is given in Eq. (1).

$$
A x^{2}+B x y+C y^{2}+D x+E y+F=0 .
$$

Here, the coefficients above must be identified. $A_{1}$ and $A_{2}$ points satisfy the conic equation. On the other hand, the safest entry point to a curved road in terms of optimum traffic parameters should be the point on which the driver's direction is tangent to curve of road. The set 
of points whose perpendicular distance (lane width) from each point on this curve is the same, will comprise the edge line connecting the points $B_{1}$ and $B_{2}$ of the direct left-turn lane. The vehicles entering the direct Evaluation of a Hybrid Roundabout Using a Microscopic turn-left lane are positioned tangentially to the inner edge line of the way at any moment of cornering. Therefore, the set of required points (the curve connecting $B_{1}$ and $B_{2}$ ) should be parallel to the conic curve as shown in Fig. 9. Surely, if necessary, the width of the turn-left lane on the central island may be increased to accommodate the passage of the vehicle.

In the conic equation represented by (1), $y$ is defined as a proper function of $x$. Then, parametric equation of proper parallel curve which is $d$ unit far from this function curve is found by using the formula given in (Lawrence, 1972). This gives the parametric representation denoting the locus of outer curve for the bend. In our study, dimension values are as provided in Table 1.

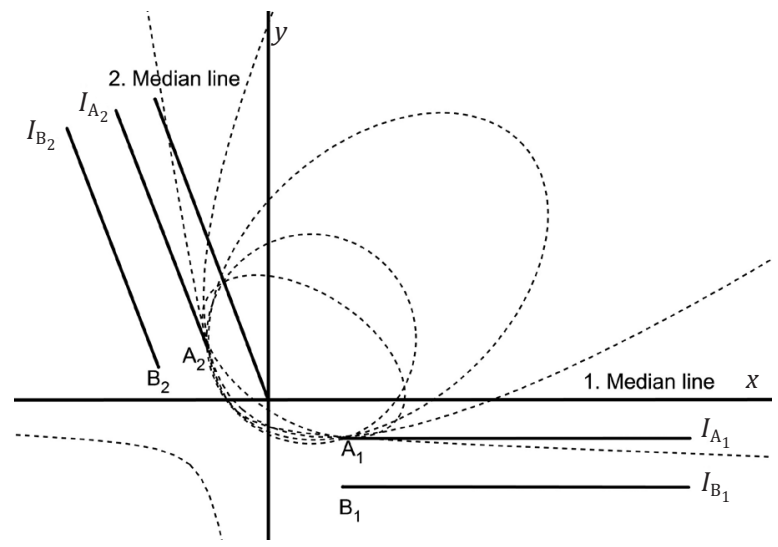

Figure 8. The conic curves connecting $A_{1}$ and $A_{2}$ curve (by $\mathrm{G}$. Tinaztepe)

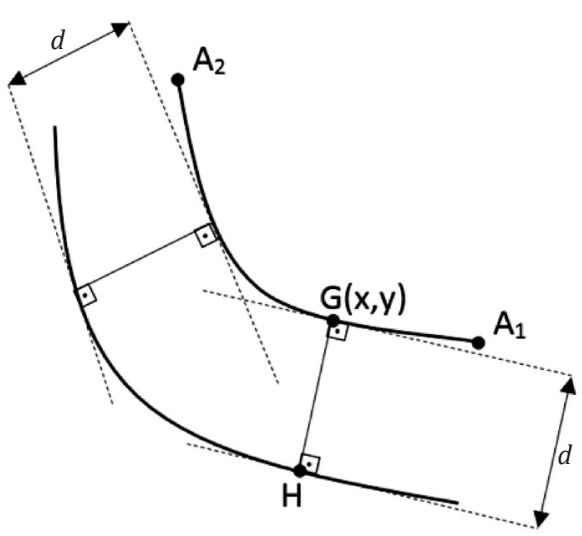

Figure 9. Direct left-turn lane (by G. Tinaztepe) 
Table 1. Geometric parameters of the roundabout used in the study

(by G. Tinaztepe)

\begin{tabular}{|c|c|c|c|}
\hline Parameter & The Status in 2016 & The Current Status & The Proposed Roundabout \\
\hline Number of legs & 4 & 4 & 4 \\
\hline Number of circulating lanes & 3 & - & 2,3 \\
\hline Number of entry lanes & $3,3,3,3$ & $2,2,4,4$ & $2,2,3,4$ \\
\hline Inscribed diameter, m & 37.6 & 38.5 & 40.12 \\
\hline Entry width, m & 10.5 & 7,14 & $7,10.5,14$ \\
\hline Circulatory road width, $m$ & 10.5 & - & $\min .7, \max .10 .5$ \\
\hline Lane width, m & 3.5 & 3.5 & 3.5 \\
\hline Entry angle, ${ }^{\circ}$ & $66-82$ & - & $37-77$ \\
\hline Central island diameter, m & 14.8 & - & - \\
\hline
\end{tabular}

In this study, $n=2.5, d=3.5 \mathrm{~m}, s_{1}=1.48 \mathrm{~m}, s_{2}=2 \mathrm{~m}, R=40.12 \mathrm{~m}$, $\alpha \approx 0.91, \alpha \approx 21.58^{\circ}$. Beginning and end points of the curves forming the direct left-turn lane on the central island are as follows: $A_{1}(-3.81,5.61)$, $\mathrm{A}_{2}(7.64,-1.48), \mathrm{B}_{1}(-7.15,4.59), \mathrm{B}_{2}(7.64,-4.98)$. Thus, the conic passing through $A_{1}$ and $A_{2}$ is calculated as the ellipse equation below:

$$
0.037223 x^{2}+0.111962 x y+0.094473 y^{2}-0.402876 x-0.651565 y+1=0 \text {. }
$$

The parametric function $[x(t), y(t)]$ of edge line of the lane, i.e., the curve connecting $B_{1}$ and $B_{2}$ points, is found as follows: for $-7.15 \leq t \leq 7.64$,

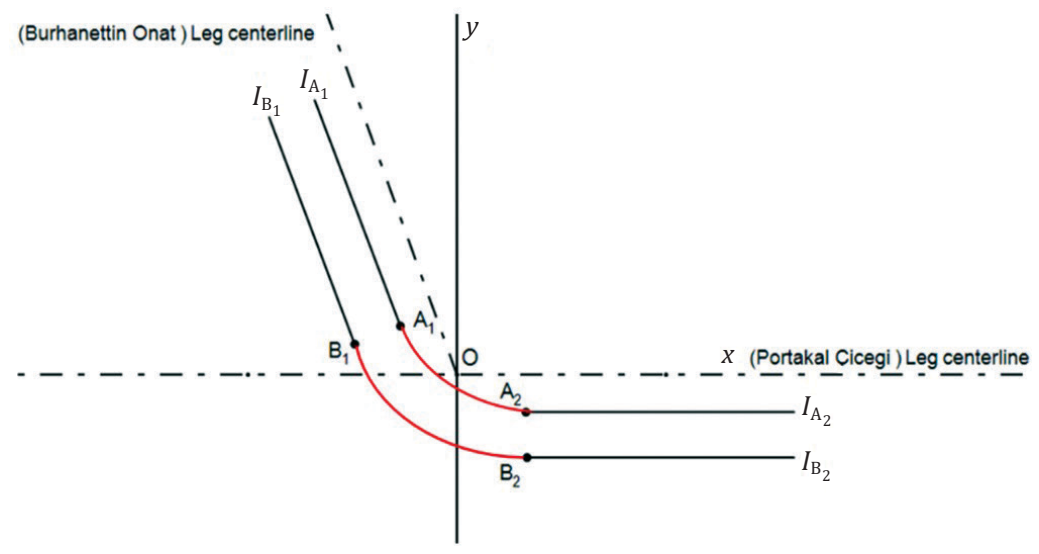

Figure 10. Drawing of the direct connection road in the proposed roundabout (by G. Tinaztepe) 


$$
\left\{\begin{array}{c}
x(t)=t-\frac{3.5[-0.008102 t+0.016783+0.59256 g(t)]}{h(t)} \\
y(t)=3.448419-0.592561 t-5.292517 g(t)-\frac{3.5 g(t)}{h(t)} \\
g(t)=\sqrt{-0.001531 t^{2}+0.006342 t+0.046645} \\
h(t)=\sqrt{-0.002003 t^{2}+0.008297 t+0.063305+(0.01989-0.009602 t) g(t)}
\end{array}\right.
$$

In the Figure 10, the intersection is drawn by using Eqs. (2) and (3). This way, vehicles can safely enter the direct connection road.

\subsection{Signal plans}

\section{The status in 2016}

The signal plan for 2016 of Burhanettin Onat Street-Metin Kasapoglu Street intersection is given in Fig. 11. The intersection runs in a 4-phase system. In the first phase, the group 1, 2, 4, 6, 12 go green as shown in Fig. 7, in the second phase the group 2, 3, 4, 8, 11, 12 go green, in the third phase the group 2, 6, 7, 8 go green and in the fourth phase the group 4,

\begin{tabular}{|c|c|c|c|c|c|c|c|c|c|c|c|c|c|c|c|c|}
\hline Groups & 1 & 2 & 3 & 4 & 5 & 6 & 7 & 8 & 9 & 10 & 11 & 12 & 13 & 14 & 15 & 16 \\
\hline Times & 2 & 46 & 2 & 2 & 2 & 55 & 2 & 2 & 2 & 26 & 2 & 2 & 2 & 19 & 2 & 2 \\
\hline Gr 1 & & & & & & & & & & & & & & & & \\
\hline Gr 2 & & & & & & & & & & & & & & & & \\
\hline Gr 3 & & & & & & & & & & & & & & & & \\
\hline Gr 4 & & & & & & & & & & & & & & & & \\
\hline Gr 5 & & & & & & & & & & & & & & & & \\
\hline Gr 6 & & & & & & & & & & & & & & & & \\
\hline Gr 7 & & & & & & & & & & & & & & & & \\
\hline Gr 8 & & & & & & & & & & & & & & & & \\
\hline Gr 9 & & & & & & & & & & & & & & & & \\
\hline Gr 10 & & & & & & & & & & & & & & & & \\
\hline Gr 11 & & & & & & & & & & & & & & & & \\
\hline Gr 12 & & & & & & & & & & & & & & & & \\
\hline
\end{tabular}
$5,6,8,9,10,12$ go green. In the phase transitions, the yellow interval is $2 \mathrm{~s}$ when switching from green to red, red interval is $2 \mathrm{~s}$ and yellow-red interval is $2 \mathrm{~s}$ when switching from red to green.

Figure 11. Software Output and intergreen times of roundabout in 2016

\section{The current status}

The signal plan for current status of the roundabout is given in Fig. 12. In this case, the intersection runs in a 3-phase system. In the first phase, the group 1, 5, 6, 8, 10 go green as shown in Fig. 8, in the second 
phase the group $2,6,9,10,1$ go green, and in the third phase the group $3,4,7,8,11,12$ go green. The group 13(F) shows the flashing red light in all phases. In the phase transitions, the yellow interval is $2 \mathrm{~s}$ when switching from green to red, red interval is $2 \mathrm{~s}$ and yellow-red interval is $2 \mathrm{~s}$ when switching from red to green.

\begin{tabular}{|c|c|c|c|c|c|c|c|c|c|c|c|c|}
\hline Groups & 1 & 2 & 3 & 4 & 5 & 6 & 7 & 8 & 9 & 10 & 11 & 12 \\
\hline Times & 2 & 55 & 2 & 2 & 2 & 62 & 2 & 2 & 2 & 26 & 2 & 2 \\
\hline Gr 1 & & & & & & & & & & & & \\
\hline Gr 2 & & & & & & & & & & & & \\
\hline Gr 3 & & & & & & & & & & & & \\
\hline Gr 4 & & & & & & & & & & & & \\
\hline Gr 5 & & & & & & & & & & & & \\
\hline Gr 6 & & & & & & & & & & & & \\
\hline Gr 7 & & & & & & & & & & & & \\
\hline Gr 8 & & & & & & & & & & & & \\
\hline Gr 9 & & & & & & & & & & & & \\
\hline Gr 10 & & & & & & & & & & & & \\
\hline Gr 11 & & & & & & & & & & & & \\
\hline Gr 12 & & & & & & & & & & & & \\
\hline Gr $13(\mathrm{~F})$ & & & & & & & & & & & & \\
\hline
\end{tabular}

Figure 12. Software Output and intergreen times of roundabout in the current status

The status of the proposed roundabout

The signal plan for the proposed roundabout is given in Fig. 13. The intersection runs in a 4-phase system. In the first phase, the group 1 and 2 go green as shown in Fig. 9, in the second phase the group 5, 6, 7, 8 go green, and in the third phase the group 2, 3, 4, 6 go green. The group 9(F) shows the flashing red light in all phases. In the phase transitions, the yellow interval is $2 \mathrm{~s}$ when switching from green to red, red interval is $2 \mathrm{~s}$ and yellow-red interval is $2 \mathrm{~s}$ when switching from red to yellow.

\begin{tabular}{|c|c|c|c|c|c|c|c|c|c|c|c|c|}
\hline Groups & 1 & 2 & 3 & 4 & 5 & 6 & 7 & 8 & 9 & 10 & 11 & 12 \\
\hline Times & 2 & 45 & 2 & 2 & 2 & 28 & 2 & 2 & 2 & 55 & 2 & 2 \\
\hline Gr 1 & & & & & & & & & & & & \\
\hline Gr 2 & & & & & & & & & & & & \\
\hline Gr 3 & & & & & & & & & & & & \\
\hline Gr 4 & & & & & & & & & & & & \\
\hline Gr 5 & & & & & & & & & & & & \\
\hline Gr 6 & & & & & & & & & & & & \\
\hline Gr 7 & & & & & & & & & & & & \\
\hline Gr 8 & & & & & & & & & & & & \\
\hline Gr9 $9(\mathrm{~F})$ & & & & & & & & & & & & \\
\hline
\end{tabular}

Figure 13. Software Output and intergreen times of roundabout for the proposed design 


\subsection{Traffic simulation parameters and calibration}

AIMSUN is an agent-based simulation program with features to simulate large urban transportation networks. In this study, the parameters to be used in AIMSUN are as shown in Table 2. ODI matrix used in simulation is given in Table 3. The data were obtained from Antalya Metropolitan Data Processing Department (Antalya Metropolitan Municipality, 2019). In this study, the pedestrian phase is not programmed as a separate phase in the signal plan of signalised intersection.

\section{Table 2. Simulation parameters}

1. Simulations are based on rush hours in the morning during 08:00-09:00 a.m.

2. The number of cars at intersection legs are entered so that they will be the same for 3 simulations, being 1593 cars at the entry leg on Burhanettin Onat Street, 1805 cars at the entry leg on Metin Kasapoglu Street, 486 cars at the entry leg on Portakal Cicegi Street, 511 cars at the entry leg on Tevfik Isık Street. Vehicle data are captured by means of counting.

3. Standard automobile class is used in the simulation.

4. Pedestrian phase was not included in the simulation.

5. AIMSUN Next 8.2.3 is used for the simulation.

6. The slope of the roads intersecting at the roundabout is assumed to be zero.

Since the signalling system works in accordance with the rule "yield to a pedestrian in the right turns", green light is burning with the vehicular phase, meaning that the pedestrian effect is negligible (Bairaboina \& Hemavathi, 2018).

Table 3. ODI matrix (between 08:00-09:00 a.m.) (by UKOME)

\begin{tabular}{cccccc}
\hline Flow Name & $\begin{array}{c}\text { Burhanettin } \\
\text { Onat Street }\end{array}$ & $\begin{array}{c}\text { Metin Kasapoglu } \\
\text { Street }\end{array}$ & $\begin{array}{c}\text { Portakal } \\
\text { Cicegi Street }\end{array}$ & $\begin{array}{c}\text { Tevfik Isık } \\
\text { Street }\end{array}$ & $\begin{array}{c}\text { Total } \\
\text { Outgoing }\end{array}$ \\
\hline Burhanettin Onat Street & 44 & 1186 & 334 & 70 & 1634 \\
Metin Kasapoglu Street & 1433 & 13 & 25 & 293 & 1764 \\
Portakal Cicegi Street & 148 & 67 & 112 & 159 & 486 \\
Tevfik Isık Street & 149 & 185 & 177 & 0 & 511 \\
Total Incoming & 1774 & 1451 & 648 & 522 & 4395 \\
\hline
\end{tabular}


Traffic volume data for the model calibration and validation test were calibrated according to the study of Geoffrey E. Havers (Department for Transport, 1997). According to the results given in Table 4, GEH criteria are implemented in this study.

Table 4. Traffic volume data in the simulation model by AIMSUN and GEH criteria (by S. Ilyas)

\begin{tabular}{ccccc}
\hline Street Name/Criterion & Observed Values & Simulation Values & GEH Values & GEH Values <5 \\
\hline \multirow{2}{*}{ Burhanettin Onat Street } & 1634 & 1453 & 4.61 & Yes \\
& 1774 & 1627 & 3.56 & Yes \\
\hline \multirow{2}{*}{ Metin Kasapoglu Street } & 1764 & 1659 & 2.54 & Yes \\
& 1451 & 1325 & 3.38 & Yes \\
\hline \multirow{2}{*}{ Portakal Cicegi Street } & 486 & 468 & 0.82 & Yes \\
\hline \multirow{2}{*}{ Tevfik Isık Street } & 648 & 579 & 2.79 & Yes \\
& 511 & 496 & 0.67 & Yes \\
\hline
\end{tabular}

Figure 14 shows the general landscape on AIMSUN software of the studying area. Bases designed with AutoCAD are used on the scaled images captured from Google Maps (Google, n. d.). Figures 15, 16 and 17 show the simulation images from AIMSUN program at different moments. These are images relating to the status in 2016, in the current status, and the proposed roundabout, respectively.

a)

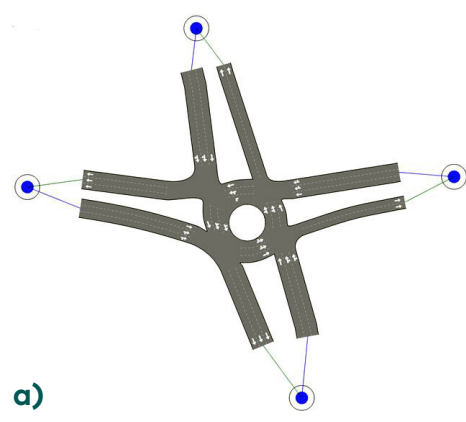

b)

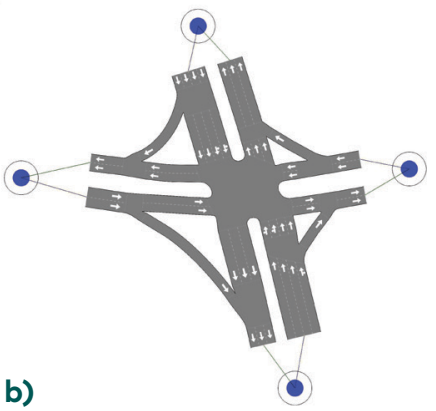

c)

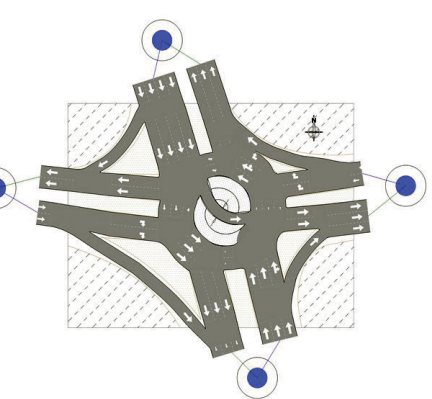

Figure 14. The subject roundabout plan drawn with AIMSUN program for a) Status in 2016 ; b) in the current status; c) the proposed type (by S. Ilyas) 

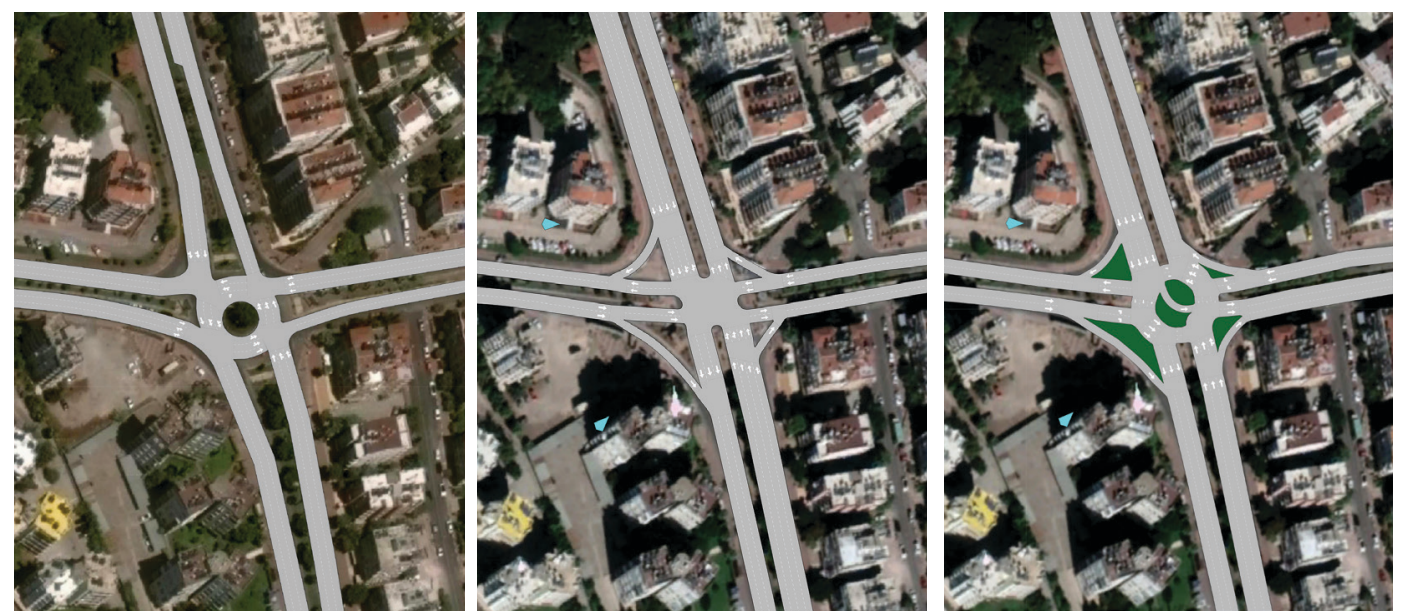

Figure 15. Simulation start images for the roundabout status in 2016, current status and the status as per the proposed roundabout (by maps.google.com)
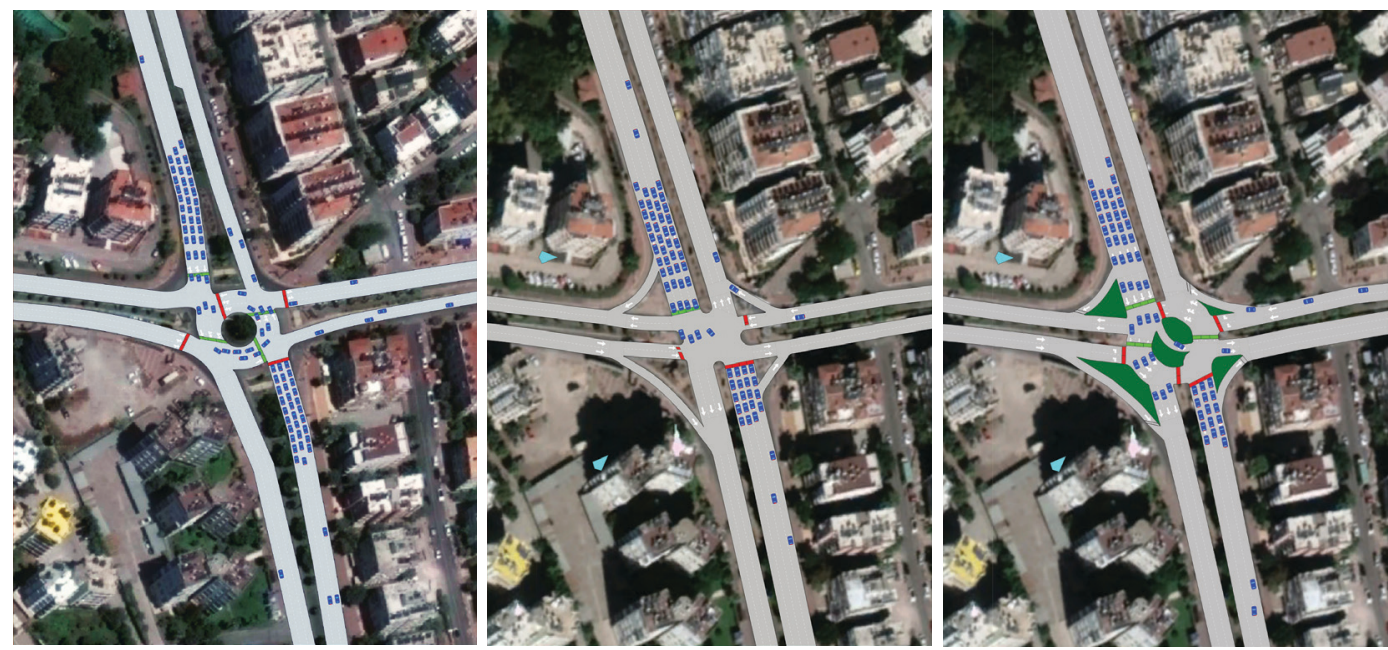

Figure 16. Simulation images for the roundabout status in 2016, in the current status and the status as per the proposed roundabout (by maps.google.com) 

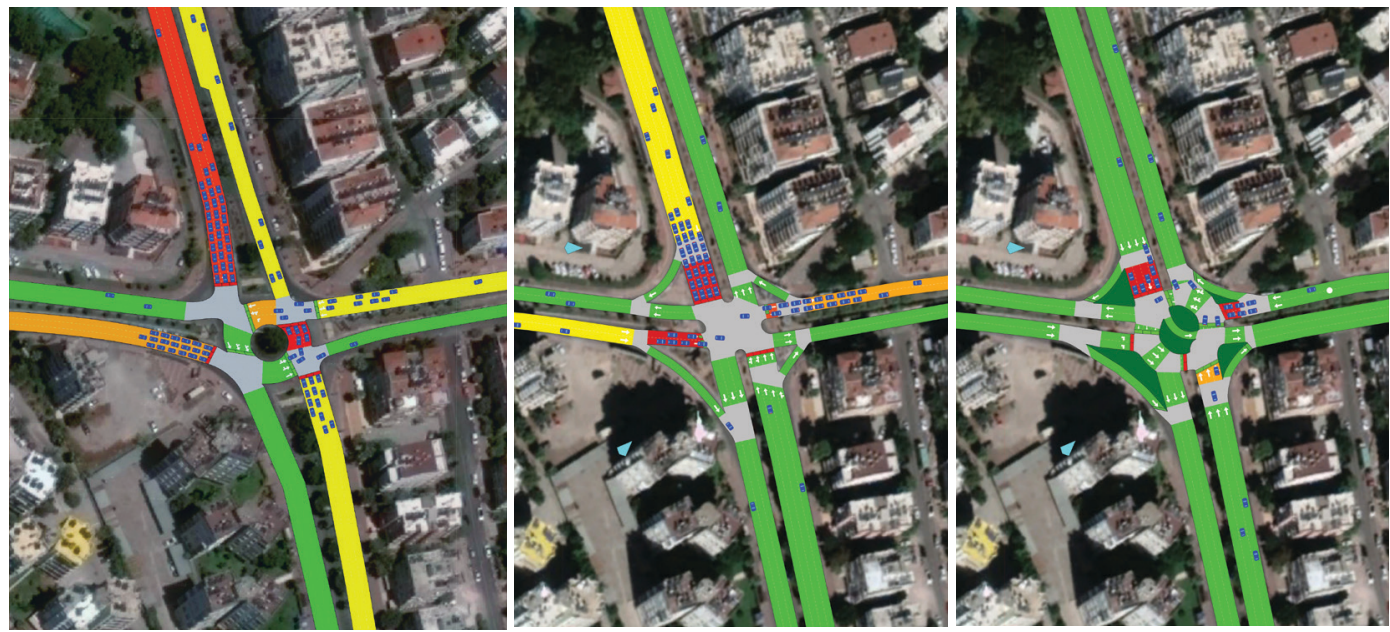

Figure 17. Coloured simulation images for the roundabout status in 2016 , in the current status and the image as per the proposed roundabout (by maps.google.com)

\section{Performance analysis}

\subsection{Analysis and comparison of traffic parameters}

Below are the traffic analyses for three different intersection types at the subject signalised roundabout: roundabout for 2016, current roundabout and the proposed roundabout, respectively. The analyses reveal that the proposed roundabout is far more successful when compared to the former roundabout types.

Figure 18 shows the average values for vehicle density-time change. Average vehicle density for 2016 is 18.88 vehicle/km, and the average for 2017 is 15.47 vehicle $/ \mathrm{km}$. In the case of the proposed roundabout, the vehicle density falls to 13.03 vehicle/ $\mathrm{km}$ with a density decrease of $31 \%$. Figure 19 shows the average figures for speed-time change. Average vehicle speed for 2016 is $25.01 \mathrm{~km} / \mathrm{h}$, and average for 2017 is $32.97 \mathrm{~km} / \mathrm{h}$. In the case of the proposed roundabout, an average vehicle speed increases up to 41.19 with a vehicle speed increase of $65 \%$. 


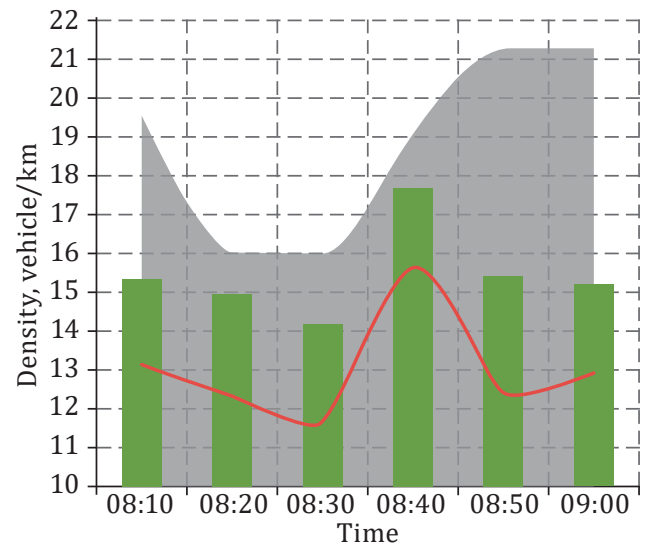

Figure 18. Vehicle density-time change

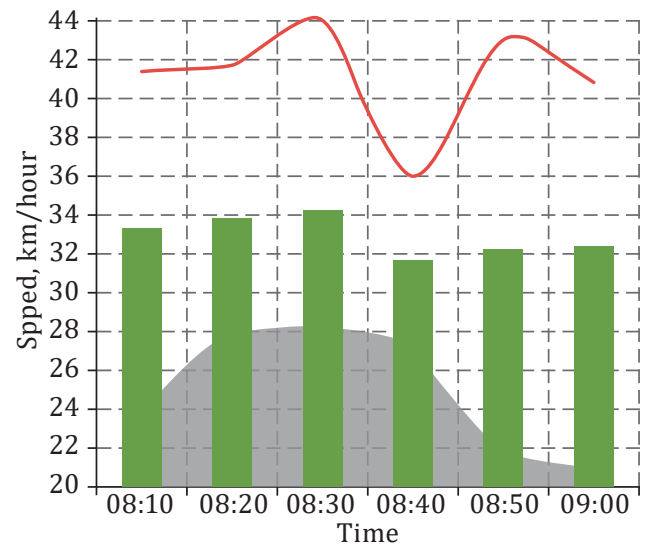

Figure 19. Speed-time change
The status for 2016

The current status

The status of the proposed roundabout
Evaluation of a Hybrid

Roundabout Using

a Microscopic

Simulation

\begin{tabular}{cccc}
\hline $\begin{array}{c}\text { The } \\
\text { status } \\
\text { for 2016 }\end{array}$ & $\begin{array}{c}\text { The } \\
\text { current } \\
\text { status }\end{array}$ & $\begin{array}{c}\text { The status of } \\
\text { the proposed } \\
\text { roundabout }\end{array}$ & Unit \\
\hline 18.88 & 15.47 & 13.03 & vehicle $/ \mathrm{km}$ \\
$100 \%$ & $81 \%$ & $69 \%$ & $\begin{array}{c}\text { percentage } \\
\text { change }\end{array}$ \\
\hline
\end{tabular}

The status for 2016

The current status

— The status of the proposed roundabout

\begin{tabular}{cccc}
\hline $\begin{array}{c}\text { The } \\
\text { status } \\
\text { for 2016 }\end{array}$ & $\begin{array}{c}\text { The } \\
\text { current } \\
\text { status }\end{array}$ & $\begin{array}{c}\text { The status of } \\
\text { the proposed } \\
\text { roundabout }\end{array}$ & Unit \\
\hline 25.01 & 32.97 & 41.19 & $\mathrm{~km} / \mathrm{hour}$ \\
$100 \%$ & $131 \%$ & $165 \%$ & $\begin{array}{c}\text { percentage } \\
\text { change }\end{array}$ \\
\hline
\end{tabular}


Figure 20 shows the average values for the number of vehicles stops. Average number of vehicles stops for 2016 is 0.48 (stops/vehicle)/h, and 0.37 (stops/vehicle)/ $\mathrm{h}$ for 2017. In the case of the proposed roundabout, the number of vehicles stops fall to 0.31 (stops/vehicle)/h with a decrease by $36 \%$ in the number of vehicles stops.

Figure 21 shows the average figures for the vehicle delay time. Average vehicle delay time for 2016 is $135.13 \mathrm{~s} / \mathrm{km}$, and $106.69 \mathrm{~s}$ for 2017. In the case of the proposed roundabout, the vehicle delay time falls to $82.73 \mathrm{~s} / \mathrm{km}$ with decrease of $39 \%$ in vehicle delay time.
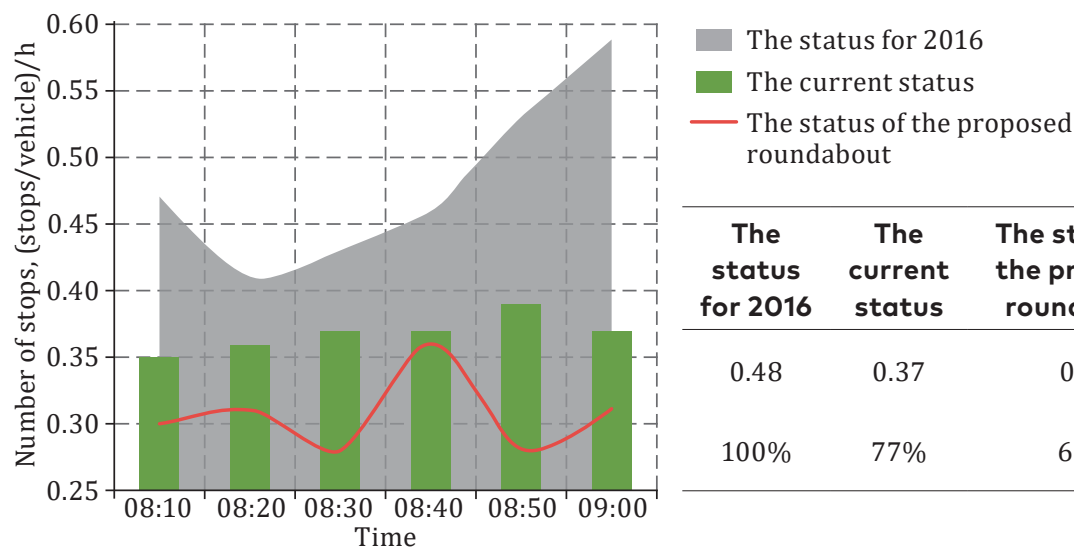

Figure 20. Number of stops-time change

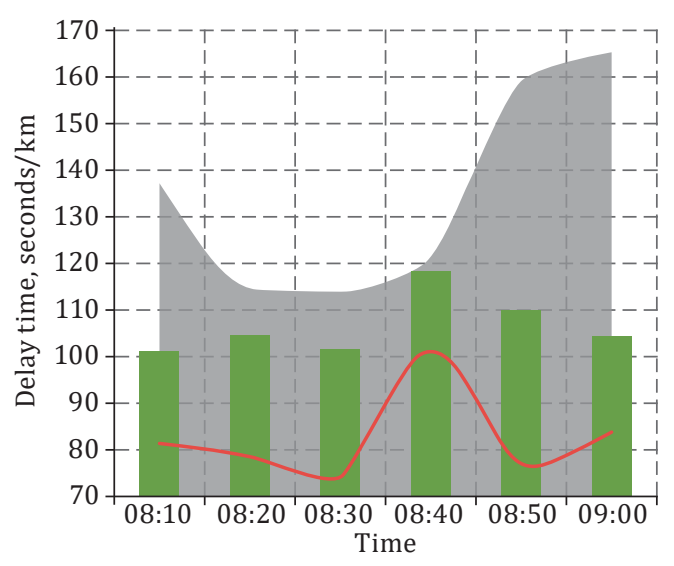

\begin{tabular}{cccc}
\hline $\begin{array}{c}\text { The } \\
\text { status } \\
\text { for } \mathbf{2 0 1 6}\end{array}$ & $\begin{array}{c}\text { The } \\
\text { current } \\
\text { status }\end{array}$ & $\begin{array}{c}\text { The status of } \\
\text { the proposed } \\
\text { roundabout }\end{array}$ & Unit \\
\hline 0.48 & 0.37 & 0.31 & $\begin{array}{c}\text { (stops/ } \\
\text { vehicle) } / \mathrm{h}\end{array}$ \\
$100 \%$ & $77 \%$ & $64 \%$ & $\begin{array}{c}\text { percentage } \\
\text { change }\end{array}$ \\
\hline
\end{tabular}

Figure 21. Vehicle delay time change 
Figure 22 shows the average figures for the vehicle fuel consumption. Average fuel consumption for 2016 is $64.22 \mathrm{~L}$ and $51.11 \mathrm{~L}$ for 2017. In the case of the proposed roundabout, average fuel consumption falls to a Microscopic $37.99 \mathrm{~L}$ with a decrease of $41 \%$ in vehicle fuel consumption.

Figure 23 shows values for average vehicle travel time. Average travel time of vehicles for 2016 is $186.43 \mathrm{~s} / \mathrm{km}$, and $159.28 \mathrm{~s} / \mathrm{km}$ for 2017 . In the case of the proposed roundabout, it falls to $122.18 \mathrm{~s}$ with a decrease of $35 \%$ in the travel time.

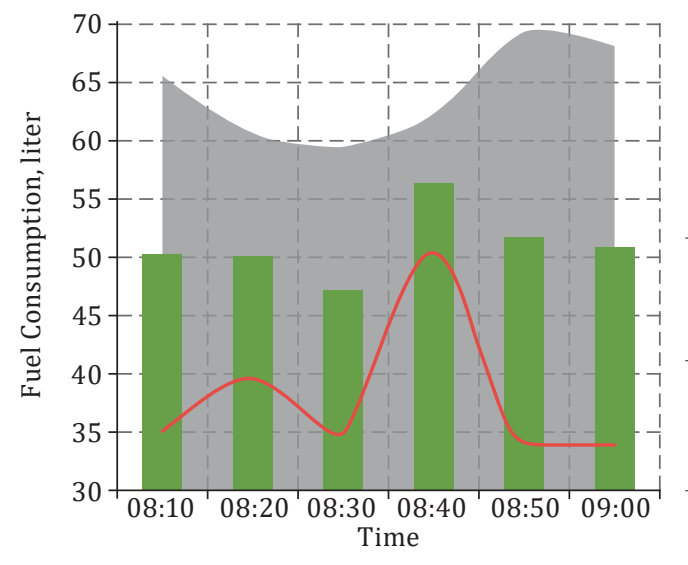
The status for 2016
The current status
- The status of the proposed roundabout

\begin{tabular}{cccc}
\hline $\begin{array}{c}\text { The } \\
\text { status } \\
\text { for } \mathbf{2 0 1 6}\end{array}$ & $\begin{array}{c}\text { The } \\
\text { current } \\
\text { status }\end{array}$ & $\begin{array}{c}\text { The status of } \\
\text { the proposed } \\
\text { roundabout }\end{array}$ & Unit \\
\hline 64.22 & 51.11 & 37.99 & liter \\
$100 \%$ & $80 \%$ & $59 \%$ & $\begin{array}{c}\text { percentage } \\
\text { change }\end{array}$ \\
\hline
\end{tabular}

Figure 22. Fuel consumption of vehicle-time change

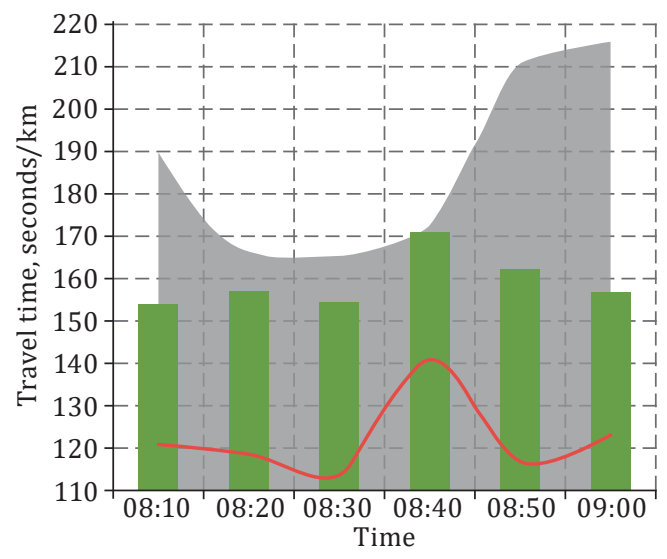

The status for 2016

The current status

- The status of the proposed roundabout

\begin{tabular}{cccc}
\hline $\begin{array}{c}\text { The } \\
\text { status } \\
\text { for 2016 }\end{array}$ & $\begin{array}{c}\text { The } \\
\text { current } \\
\text { status }\end{array}$ & $\begin{array}{c}\text { The status of } \\
\text { the proposed } \\
\text { roundabout }\end{array}$ & Unit \\
\hline 186.43 & 159.28 & 122.18 & $\begin{array}{c}\text { seconds } / \mathrm{km} \\
\text { percentage } \\
\text { change }\end{array}$ \\
\hline $100 \%$ & $86 \%$ & $65 \%$ & \begin{tabular}{c} 
chang \\
\hline
\end{tabular}
\end{tabular}

Figure 23. Vehicle travel time change 
Figure 24 shows the average figures for carbon emission of vehicles. Average carbon emission for 2016 is $126617.1 \mathrm{~g}$, and $105127.3 \mathrm{~g}$ for 2017. In the case of the proposed roundabout, average carbon emission falls to $83637.3 \mathrm{~g}$ with a decrease of $44 \%$ in carbon emission of vehicles.

Figure 25 shows the figures for mean queue of vehicles. Mean queue for 2016 is 60.4 vehicles, and 37.57 vehicles for 2017. In the case of the proposed roundabout, mean queue falls to 28.02 vehicles with a decrease of $46 \%$ in mean queue of vehicles.

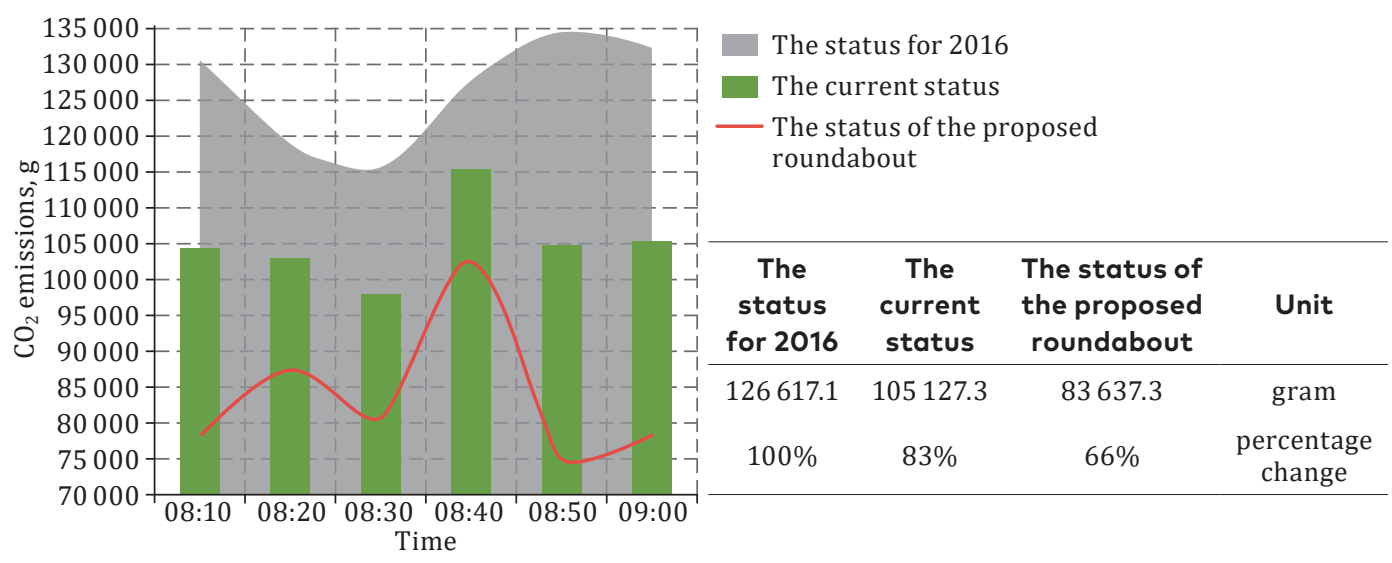

Figure 24. Carbon emission of vehicle-time change

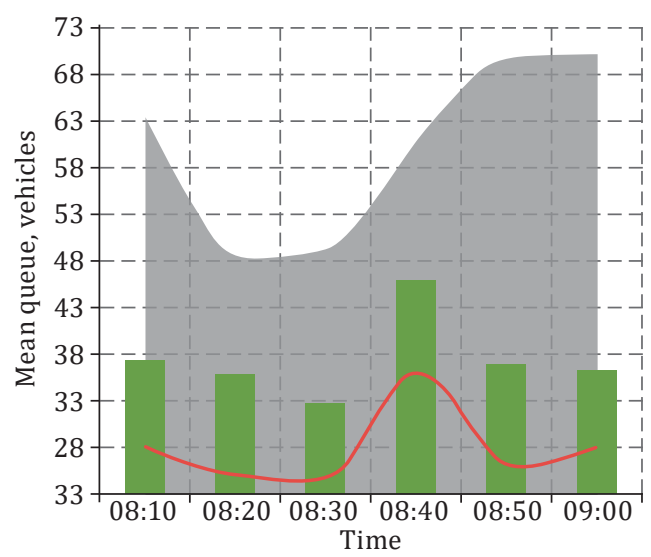

The status for 2016

The current status

— The status of the proposed roundabout

\begin{tabular}{cccc}
\hline $\begin{array}{c}\text { The } \\
\text { status } \\
\text { for } 2016\end{array}$ & $\begin{array}{c}\text { The } \\
\text { current } \\
\text { status }\end{array}$ & $\begin{array}{c}\text { The status of } \\
\text { the proposed } \\
\text { roundabout }\end{array}$ & Unit \\
\hline 60.40 & 37.57 & 28.02 & vehicle \\
$100 \%$ & $62 \%$ & $46 \%$ & $\begin{array}{c}\text { percentage } \\
\text { change }\end{array}$ \\
\hline
\end{tabular}

Figure 25. Mean queve-time change 


\subsection{Traffic safety analysis}

Performance

Evaluation of a Hybrid

Roundabout Using

a Microscopic

For years, roundabouts have been one of the prioritised control systems used for offering a solution to the problems of traffic engineering all around the world. Roundabouts are directed intersections where the traffic flows counter clockwise (in the case of right-hand traffic) or clockwise (in the case of left-hand traffic), generally around a circular island (Janssens, 1994). Roundabouts offer many advantages with regard to traffic safety. For an intersection with four approach legs, while the number of conflict points is thirty in case the intersection is uncontrolled, the number of conflict points is only eight in case the intersection is designed in the form of a roundabout. This clearly demonstrates that roundabout is a type of intersection, which is highly efficient in terms of achieving traffic safety (Gross et al., 2013).

This part of the study analyses the intersection conflict points per the driver behaviours. If the signalised intersection runs in flash mode during night hours when traffic density is quite low, the safety analysis data become even more significant. As the number of conflict points increases, the possibility of traffic accident increases, too. Figure 26 shows the conflict points for all the statutes of roundabout. For the status in 2016, there are a total of 75 conflict points with 17 merging points, 14 diverging points, 44 crossing points and for the current status in 2017 and after, there are a total of 54 conflict points with 7 merging points, 6 diverging points, 41 crossing points, and for the proposed roundabout, there are a total of 44 conflict points with 11 merging points, 11 diverging points and 22 crossing points.
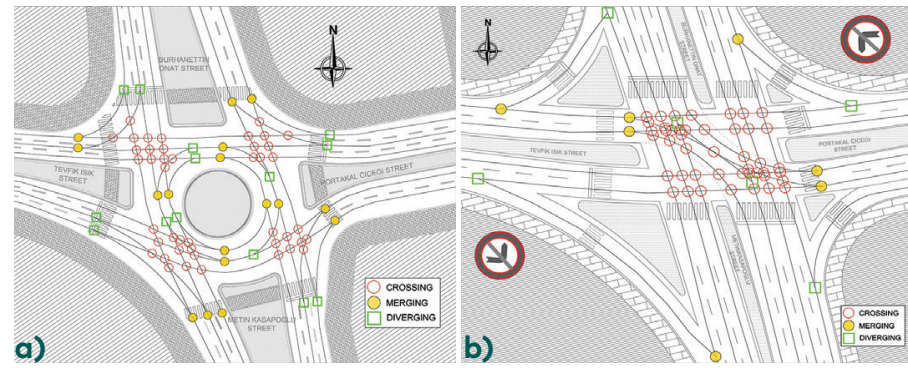

b)

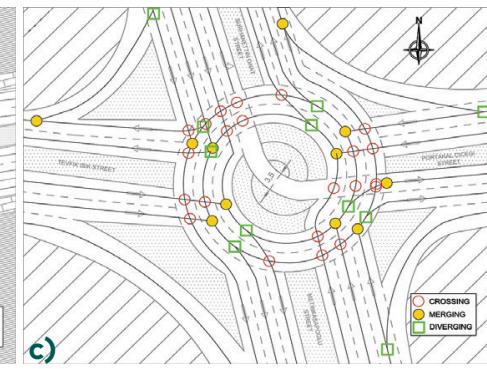

c)

Figure 26. Conflict points for the roundabout: a) the status for 2016; b) the current status; c) the status for the proposed type (by Y. User \& S. Ilyas) 


\section{Results and discussion}

This study has analysed and compared 3 roundabout type statuses, which are the status in 2016, current status and the status of the proposed intersection, for the signalised roundabout located in Antalya, Burhanettin Onat Street-Metin Kasapoglu Street, that is Sampi intersection, using AIMSUN. The roundabout in 2016 and in 2017 and after is commonly used today. The three simulations applied using the same conditions have shown that the proposed roundabout provides the most efficient results. A union of two Archimedes spirals was used as the geometric structure of circulatory lanes in accordance with the turbo roundabout feature of a hybrid junction. Then, a left-turn lane passing through a central island from Burhanettin Onat arm to the Portakal Cicegi arm was added in accordance with the hamburger throughabout feature of a hybrid function. The conic curve was used for the geometric structure of this left turning lane on the central island.

Key characteristics of turbo and hamburger type roundabouts available in the literature are combined in a single intersection type. The proposed roundabout combines the key characteristic of turbo type intersection, which is safety for the traffic and drivers, by placing the transit pass into the turbo roundabout island, and the traffic-relieving characteristic of the hamburger type roundabout.

When the proposed roundabout is compared to the current status, during rush hours in the morning from 08:00- 09:00 a.m., average vehicle density decreased by $12 \%$ from 15.47 vehicle $/ \mathrm{km}$ to 13.03 vehicle/ $\mathrm{km}$, an average vehicle speed increased by $34 \%$ from $32.97 \mathrm{~km} / \mathrm{h}$ to $41.19 \mathrm{~km} / \mathrm{h}$, an average number of vehicle stops decreased by $13 \%$ from 0.37 (stops/vehicle)/h to 0.31 (stops/vehicle)/h, and the average delay time decreased by $18 \%$ from $109.69 \mathrm{~s} / \mathrm{km}$ to $82.73 \mathrm{~s} / \mathrm{km}$, average fuel consumption of vehicles decreased by $21 \%$ from $51.11 \mathrm{~L}$ to $37.99 \mathrm{~L}$ and the average travel time of vehicles decreased by $21 \%$ from $159.28 \mathrm{~s} /$ $\mathrm{km}$ to $122.18 \mathrm{~s} / \mathrm{km}$. More importantly, the traffic flow has relieved, and fuel consumption and traffic gas emission to the environment have reduced.

The left-turn lane passing through the central island has reduced the traffic volume of urban arterial streets in Burhanettin Onat-Metin Kasapoglu direction. Although it is not the arterial street, Portakal Cicegi street is frequently used as the quickest way from the roundabout to access the developing tourism district, Lara, instead of Metin Kasapoglu Street. In the next years, it is estimated that the traffic volume on this street will increase.

With the removal of the central island of the roundabout in 2016, the average values for travel time, number of stops, vehicle density, fuel 
consumption, delay time, conflict point, carbon emission parameters, except vehicle speed changes, were positively affected by $19 \%$. Average vehicle speed increased by $31 \%$. In the proposed roundabout, the Evaluation of a Hybrid Roundabout Using a Microscopic average speed of the vehicles increased by $65 \%$ in comparison with the status in 2016, and the performance of the average fuel consumption was affected more positively in comparison with the other parameters.

In the current status of intersection where there is no central island, the number of conflict points increased by $28 \%$ and reached 41 in comparison with the status in 2016. Although the merging points and diverging points have increased in the proposed roundabout, the conflict points have decreased by $53 \%$ due to the features of the turbo roundabout geometry. According to the number of conflict points that determine the accident risk, the proposed roundabout is $41 \%$ safer than the status in 2016, and the accident risk is $18.5 \%$ lower than the current status.

Figure 27 shows all analyses in the same graphic to make sure that results are seen and comparison is understood better. Average values for travel time, number of stops, speed, vehicle density, fuel consumption, delay time, conflict point, carbon emission given in Part 3 are provided in the same chart. The change in speed in the proposed hybrid junction is more clearly seen in comparison with other performance parameters.

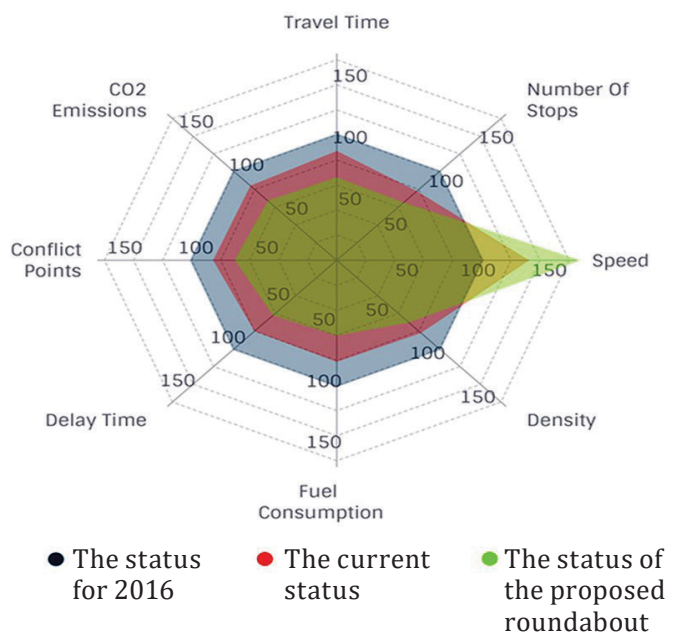

Figure 27. All analyses in one chart 


\section{Conclusion}

In this study, the performance of the proposed roundabout has been analysed using the AIMSUN and compared with the status in 2016 and the current status of the roundabout. Signal planning works in a 4-phase system for the status of intersection in 2016 and for the proposed roundabout and works in a 3-phase system for the current status of the roundabout. The summary of the results is given in the following items.

1. Advances in technology lead to rapid increment in the speed, types and performance of new vehicles and the population growth yields to an increase in the number of vehicles. Correspondingly, security and public responsibilities are of great importance due to the increasing traffic. When the literature is reviewed, it is seen that many researchers from different countries are in search of various intersection types to address this issue.

2. There are many alternative types of intersections in the literature. These types have different superior characteristics. New hybrid intersection types combining the superior features of current intersection types can be developed and analysed, especially with the development of microscopic simulation techniques giving realistic results. As a result of the application of the proposed roundabout type, especially, vehicle speeds have increased, queuing and conflict points have decreased. This type of studies is attracting attention and will increase in the future.

3. Roundabout performance has increased with the removal of the classic island in the status of roundabout in 2016 in comparison with the current status. Instead of using the conventional roundabout that is common in Turkey, the removal of the central island and usage of signalised junction will be more feasible. In this regard, it is monitored that average vehicle density, average vehicle speed, average number of vehicle stops, average delay time, average fuel consumption of vehicles, average travel time of vehicles, average carbon emission of vehicles, mean queue improved by $19 \%, 31 \%, 33 \%, 21 \%, 14 \%, 21 \%, 17 \%, 38 \%$, respectively. The removal of the centre island increased its average overall performance by $24 \%$.

4. With the redesigning of the roundabout as the proposed type, the performance of the current status of the roundabout has improved further. In this context, it is observed that average vehicle density, average vehicle speed, average number of vehicle stops, average delay time, average fuel consumption of vehicles, average travel time of vehicles, average carbon emission of vehicles, mean queue improved by $12 \%, 34 \%, 13 \%, 18 \%, 21 \%, 21 \%, 17 \%, 16 \%$, 
respectively. The average overall performance has increased by $19 \%$.

Evaluation of a Hybrid

Roundabout Using

a Microscopic

5. In the status of the roundabout in 2016, while the vehicles coming from Burhanettin Onat and entering the roundabout for left-turn should have circulated more than half of the roundabout, they directly pass to the Portakal Çiçeği Street owing to the proposed hybrid design. Thanks to the direct left-turn lane, the number of vehicles coming from Burhanettin-Onat and entering the roundabout decreased by $20 \%$. This reduces the risk of accidents caused by vehicles circulating the roundabout.

6. The layout of the intersection has been considered in Cartesian coordinate system and the geometric template for the proposed roundabout has been designed. On the layout, the selection of transit left-turn connection points $\left(A_{1}\right.$ and $A_{2}$ in Fig. $\left.7 a\right)$ on the spiral and the design of the left-turning lane passing through the central island have been made. Since an ellipse arc has been used in designing this lane on the island instead of a circle arc, the curvature will be relatively less, left turning vehicles can exit the roundabout at a higher speed. Also, the width of the lane on the central island can be extended so that long vehicles can turn.

7. The major arterial traffic flow on the roundabout is in the axis of Burhanettin Onat and Metin Kasapoglu streets. Owing to a decrease in the average number of vehicle stops by $13 \%$, there is an increase in the average vehicle speed by $34 \%$, the average mean queue has decreased by $18 \%$. Thanks to the left-turn lane on the central island from Burhanettin Onat Street to Portakal Cicegi Street, there will be a remarkable relief of major arterial traffic flow, which increases especially in tourism seasons.

8. When the safety analysis is compared according to driver behaviour, the proposed roundabout has a smaller number of conflict points compared to 2016 and the current status. Thus, the accident risk decreased by $41.3 \%$ on average. Turbo roundabout geometry has provided the reduction in conflict points for the proposed roundabout. In addition, the risk of accidents will be much lower in the flash mode application at night times, when the traffic flow is minimum.

To sum up, this study presents the results of traffic safety and efficiency analysis after the combination of the geometric features of two alternative roundabout types, namely, turbo and hamburger, is performed on a four-leg conventional roundabout.

In the future, by considering the additional factors (e.g., population growth, uncertainty of driver behaviour, construction costs, traffic flow distribution and pollution) with more realistic data from field studies, 
modelling and research can be performed on new hybrid roundabouts designed by means of combination of certain types of the roundabouts.

\section{Acknowledgements}

The authors would like to thank Akdeniz University BAP Coordination Unit for their support for the Research Project with ID FYL-2018-2748 and also Antalya Metropolitan Municipality, Department of Transportation Planning and Rail Systems for their support with the experiments.

\section{Funding}

The research has been sponsored by the BAP (Scientific Research Project Coordination Unit of Akdeniz University, Turkey) with the project code FYL-2018-2748.

\section{REFERENCES}

Aakre, E., \& Aakre, A. (2017). Simulating Transit Priority: Continuous Median Lane Roundabouts. Procedia Computer Science, 109, 849-854. https://doi.org/10.1016/j.procs.2017.05.400

Antalya Metropolitan Municipality. (2019). Annual Average Traffic Values and Transportation Information According to Traffic Segments of Motorways and State Roads. UKOME (Transportation Coordination Center).

Brown, M. (1995). The Design of Roundabouts. HMSO, TRL.

Bai, Y., Chen, W., \& Xue, K. (2010). Association of Signal-Controlled Method at Roundabout and Delay. In 2010 International Conference on Intelligent Computation Technology and Automation. IEEE. https://doi.org/10.1109/ICICTA.2010.510

Bairaboina, S. S. R., \& Hemavathi, D. (2018, November). Driver's Behaviour Analytics in the Traffic Accident Risk Evaluation. In International Conference on Computational Vision and Bio Inspired Computing (pp. 1355-1361). Springer, Cham. https://doi.org/10.1007/978-3-030-41862-5_139

Chenwei, Z., \& Xiaodan, M. (2017). Establishment and Practice of Delay Model of Hamburger Roundabout. Agricultural Equipment \& Vehicle Engineering, 09.

Corriere, F., \& Guerrieri, M. (2012). Performance Analysis of Basic Turbo-Roundabouts in Urban Context. Procedia - Social and Behavioral Sciences, 53, 622-632. https://doi.org/10.1016/j.sbspro.2012.09.912

Dabiri, A. R., Aghayan, I., \& Hadadi, F. (2020). A Comparative Analysis of the Performance of Turbo Roundabouts Based on Geometric Characteristics and Traffic Scenarios. Transportation Letters, 1-12. 
https://doi.org/10.1080/19427867.2020.1757198

De Brabander, B., \& Vereeck, L. (2007). Safety Effects of Roundabouts in Flanders: Signal Type, Speed Limits and Vulnerable Road Users. Accident Analysis and Prevention, 39(3), 591-599.

https://doi.org/10.1016/j.aap.2006.10.004

Department for Transport. (1997). Design Manual for Roads and Bridges, Volume 12, Sections 1 and 2. UK.

Džambas, T., Ahac, S., \& Dragčević, V. (2017). Geometric Design of Turbo Roundabouts. Tehnicki Vjesnik, 24(1), 309-318.

https://doi.org/10.17559/TV-20151012162141

Elhassy, Z., Abou-Senna, H., Shaaban, K., \& Radwan, E. (2020). The Implications of Converting a High-Volume Multilane Roundabout into a Turbo Roundabout. Journal of Advanced Transportation, 2020, 1-12. https://doi.org/10.1155/2020/5472806

Ess, J., \& Antov, D. (2017). Estonian Traffic Behaviour Monitoring Studies 2001-2016: Overview and Results. The Baltic Journal of Road and Bridge Engineering, 12(3), 167-173. https://doi.org/10.3846/bjrbe.2017.20

Fortuijn, L. G. (2009). Turbo Roundabouts: Design Principles and Safety Performance. Transportation Research Record, 2096(1), 16-24. https://doi.org/10.3141/2096-03

Google. (n. d.). Sampi Roundabout. Google. https://www.google.com.tr/maps/@36.8734303,30.7187042,19.5z

Gross, F., Lyon, C., Persaud, B., \& Srinivasan, R. (2013). Safety Effectiveness of Converting Signalized Intersections to Roundabouts. Accident Analysis and Prevention, 50, 234-241. https://doi.org/10.1016/j.aap.2012.04.012

Goncharenko, A. V. (2018). Airworthiness Support Measures Analogy to the Prospective Roundabouts Alternatives: Theoretical Aspects. Journal of Advanced Transportation, 2018, Article ID 9370597. https://doi.org/10.1155/2018/9370597

Hatami, H., \& Aghayan, I. (2017). Traffic Efficiency Evaluation of Elliptical Roundabout Compared with Modern and Turbo Roundabouts Considering Traffic Signal Control. Promet - Traffic \& Transportation, 29(1), 1-11. https://doi.org/10.7307/ptt.v29i1.2053

Izadi, A., Mirzaiyan, D., Rashidi, A., \& Hosseini, M. (2016). Comparing Traffic Performances of Turboroundabouts and Conventional Roundabout (Case Study). Turk. Online J. Des. Art. Commun., 6, 598-604. https://doi.org/10.7456/1060JSE/026

Janssens, R. (1994). Evaluating the Performance of a Roundabout. In CEEC's Training Seminar on Road Development and Safety for Managerial Staff from Central and Eastern European Countries. Brussels, Belgium.

Kettil, P., \& Wiberg, N. E. (2002). Application of 3D Solid Modeling and Simulation Programs to a Bridge Structure. Engineering with Computers, 18(2), 160-169. https://doi.org/10.1007/s003660200014

Kolak, I., Ištoka Otković, I., \& Barišić, I. (2015). Using a Microsimulation Traffic Model to Compare Two-Lane and Turbo-Roundabouts. Electronic Journal of the Faculty of Civil Engineering Osijek-e-GFOS, 6(11), 71-80.

https://doi.org/10.13167/2015.11.8
Performance

Evaluation of a Hybrid

Roundabout Using

a Microscopic

Simulation 
Lee, J., Rouphail, N., \& Foyle, R. (2003). Capturing Lane Performance at Signalized Intersections Using Current HCM Methods and Software. 82nd Annual Meeting of the Transportation Research Board.

Liu, Q., Deng, J., Shen, Y., Wang, W., Zhang, Z., \& Lu, L. (2020). Safety and Efficiency Analysis of Turbo Roundabout with Simulations Based on the Lujiazui Roundabout in Shanghai. Sustainability, 12(18), 7479. https://doi.org/10.3390/su12187479

Lawrence, J. D. (1972). A Catalog of Special Plane Curves. Dover Publishers.

Mandavilli, S., Rys, M. J., \& Russell, E. R. (2008). Environmental Impact of Modern Roundabouts. International Journal of Industrial Ergonomics, 38(2), 135-142. https://doi.org/10.1016/j.ergon.2006.11.003

Mauro, R., \& Branco, F. (2010). Comparative Analysis of Compact Multilane Roundabouts and Turbo-Roundabouts. Journal of Transportation Engineering, 136(4), 316-322. https://doi.org/10.1061/(ASCE)TE.1943-5436.0000106

Qian, H. B., Li, K. P., \& Sun, J. (2008). The Development and Enlightenment of Signalized Roundabout. In Proceedings of the International Conference on Intelligent Computation Technology and Automation (ICICTA 2008) (pp. 538-542). https://doi.org/10.1109/ICICTA.2008.49

Silva, A. B., Vasconcelos, L., \& Santos, S. (2014). Moving from Conventional Roundabouts to Turbo-Roundabouts. Procedia - Social and Behavioral Sciences, 111, 137-146. https://doi.org/10.1016/j.sbspro.2014.01.046

Skvain, V., Petru, J., \& Krivda, V. (2017). Turbo - Roundabouts and Their Basic Evaluation at Realized Constructions in Czech Republic. Procedia Engineering, 190, 283-290. https://doi.org/10.1016/j.proeng.2017.05.339

Tollazzi, T., Jovanović, G., \& Renčelj, M. (2013). New Type of Roundabout: Dual One-Lane Roundabouts on Two Levels with Right-Hand Turning Bypasses - "Target Roundabout". Promet - Traffic \& Transportation, 25(5), 475-481. https://doi.org/10.7307/ptt.v25i5.1230

Tollazzi, T., Mauro, R., Guerrieri, M., \& Rençelj, M. (2016). Comparative Analysis of Four New Alternative Types of Roundabouts: "Turbo", "Flower", "Target" and "Four-Flyover" Roundabout. Periodica Polytechnica Civil Engineering, 60(1), 51-60. https://doi.org/10.3311/PPci.7468

Tollazzi, T. (2014). Modern Types of Roundabouts - Trends and Future Expectations. In III International Conference "Traffic Safety in the Local Community". Banja Luka, 30-31 October 2014.

Tollazzi, T., \& Rencelj, M. (2014). Comparative Analyse of the Two New Alternative Types of Roundabouts - Turbo and Flower Roundabout. The Baltic Journal of Road and Bridge Engineering, 9(3), 164-170. https://doi.org/10.3846/bjrbe.2014.21

Tollazzi, T., \& Rencelj, M. (2014). Modern and Alternative Types of Roundabouts State of the Art. In 9th International Conference on Environmental Engineering (ICEE 2014). https://doi.org/10.3846/enviro.2014.137

Vasconcelos, L., Silva, A. B., Seco, Á. M., Fernandes, P., \& Coelho, M. C. (2014). Turboroundabouts: Multicriterion Assessment of Intersection Capacity, Safety, and Emissions. Transportation research record, 2402(1), 28-37. https://doi.org/10.3141/2402-04 
Wu, Y., Lu, J., Chen, H., \& Yang, H. (2015). Development of an Optimization Traffic Signal Cycle Length Model for Signalized Intersections in China. Mathematical Problems in Engineering, 2015, 1-9. https://doi.org/10.1155/2015/954295
Performance

Evaluation of a Hybrid Roundabout Using a Microscopic Simulation

\section{Nomenclature \& Symbols}

$a$ - spiral equation coefficient;

$r$-spiral radius;

$\theta$ - spiral angle;

$\alpha$ - the angle between $y$ axis and leg center line;

$\mathrm{A}_{1}$ - connection point for direct road;

$\mathrm{A}_{2}$ - connection point for direct road;

$\mathrm{B}_{1}$ - connection point for direct road;

$\mathrm{B}_{2}$ - connection point for direct road;

$I_{\mathrm{A}_{1}}$ - edge line for lane;

$I_{\mathrm{A}_{2}}$ - edge line for lane;

$I_{\mathrm{B}_{1}}$ - edge line for lane;

$I_{\mathrm{B} 2}$ - edge line for lane;

$R$ - inscribed diameter of roundabout;

$S_{1}-$ distance between 1 st centreline and $I_{\mathrm{A}_{1}}$;

$S_{2}$ - distance between 2 nd centreline and $I_{\mathrm{A}_{2}}$;

$d$ - width of lane or width of direct connection road. 